\title{
Los inicios de la presencia fenicia en Cádiz
}

\author{
Aurelio Padilla Monge \\ Universidad de Sevilla \\ apadilla@us.es
}

Recibido: 7 de junio de 2014

Aceptado: 30 de agosto de 2014

\section{RESUMEN}

Defiendo en este artículo la hipótesis de que las edificaciones levantadas por los fenicios en el extremo norte de la actual península de Cádiz, en el paso del siglo IX al VIII a.C., estuvieron fundamentalmente dedicadas a las actividades cultuales desarrolladas por los cananeos asentados en la colonia de Doña Blanca y a labores pesqueras y de procesado de las capturas; del mismo modo, arguyo que estas instalaciones terminarían por convertirse, a lo largo del siglo VI a.C., en una entidad poblacional de cierta importancia desde el punto de vista demográfico, como consecuencia del aporte poblacional recibido desde las colonias fenicias ubicadas en el Bajo Guadalquivir y la zona de Huelva, territorio en el que se produjo el colapso del mundo colonial cananeo, y en un centro de cierta preeminencia desde el punto de vista político-económico, en gran medida como consecuencia de la desaparición de dicho horizonte colonial.

Palabras clave: Colonización fenicia. Península Ibérica prerromana. Gadeira. Gadir. Gades.

\section{The beginnings of the Phoenician presence in Cadiz}

\begin{abstract}
I defend in this paper the hypothesis that the structures set up by the Phoenicians in the North of the present peninsula of Cadiz, from the late ninth century or early eighth century B.C. onward, were mainly devoted to the religious activities of the settlers established in the colony of Doña Blanca and that fish processing labours were also carried out in the ancient island of Cadiz. Likewise, I argue that these buildings became, over the course of the sixth century B.C., both an important population entity from a demographic point of view, on account of the arrival of people from the Phoenician colonies sited in the Low Guadalquivir and the area of Huelva, a territory in which the Canaanite colonial world collapsed, and an important centre from a political and economic point of view, to a great extent due to the disappearance of the quoted colonial horizon.
\end{abstract}

Key words: Phoenician colonization. Pre-Roman Iberian Peninsula. Gadeira. Gadir. Gades.

Sumario: 1. Introducción. 2. Paleogeografía gaditana. 3. Arqueología y Paleotoponimia fenicio-púnica: Gadir. 4. Paleogeografía y Paleotoponimia greco-latina. 5. Cronología, Literatura y Arqueología. 6. Un sitio para los dioses y los atuneros. 7. Santuarios. 8. Pesca y salazones. 9. El ascenso de Gadir. 10.

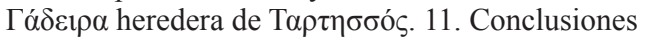




\section{Introducción}

Parte de la investigación dedicada a la presencia de $\operatorname{los}_{\text {fenicios }}{ }^{1}$ en la Península Ibérica sostiene que todos los indicadores arqueológicos sugieren la existencia, durante los siglos IX-VII a.C., de dos categorías de asentamientos coloniales: una mayoritaria, integrada por los puertos comerciales situados en la costa mediterránea, y otra constituida por una única colonia, Gadir, entendiendo por Gadir el antecedente histórico de la actual ciudad de Cádiz, que presentaría un status claramente diferenciado del resto. ${ }^{2}$ Incluso se sostiene que la situación de preeminencia se instituyó desde el mismo inicio de la implantación colonial, concretada precisamente en la fundación de Gadir, y se debió al liderazgo que el Estado de Tiro tuvo en el proceso colonial en Occidente, coordinado y supervisado desde Gadir y su santuario. ${ }^{3}$ Pero, ante la falta de datos concluyentes en este sentido, me surge la duda de si la función de $G a$ dir como centro supervisor y coordinador del proceso colonizador tirio realmente existió o es únicamente un paradigma historiográfico que, de acuerdo con los datos arqueológicos que hoy día están a disposición de la investigación, tiene un alternativa plausible.

\section{Paleogeografía gaditana}

Las conclusiones de los estudios paleogeográficos de la bahía de Cádiz sostienen que, desde antes del siglo IX a.C., había una única isla, resultado de la unión de una antigua isla de pequeño tamaño, conectada por un istmo a otra isla, de mayor tamaño y ubicada al sur de la anterior, que era a su vez el resultado de la unión de tres antiguas islas, que podemos llamar de Cádiz, de León o de San Fernando y de Campo Soto; es decir, el brazo de mar conocido como canal Bahía-Caleta, que separó en su momento ambas islas, estaba colmatado y cegado por la zona central, de modo que la antigua isla de pequeño tamaño estaba sólidamente unida a la isla mayor, ${ }^{4}$ aunque subsistían dos ensenadas: una que miraba hacia Poniente y otra que lo hacía hacia la bahía. ${ }^{5}$ La ensenada que miraba hacia Levante llegaba hasta poco más allá del lugar hoy ocupado por la calle José Celestino Mutis y penetraba un poco en los terrenos en los que se eleva actualmente el edificio de la Universidad de Cádiz, como documenta la perforación CAD 602, realizada en la plaza de Cañamaque. ${ }^{6}$ Por su parte, la ensenada orientada hacia Poniente quedó inundada en su momento por las aguas marinas, junto

1 Los fenicios o fenkhu aparecen identificados como habitantes de Siria ya en el Libro de los Muertos (Wallis Budge 1991, 156), en una estela del rey Ahmés I (Nebpehtyra Ahmes; ca. 1552-1526 a.C.) hallada en al-Maasara: tau fenkhu o 'país de los fenicios' (Urk. IV, 25.12); y en una inscripción de Thutmés II (Aakheperenra Djehutymes, ca. 1493-1478 a.C.) hallada entre Asuán y File: tau fenkhu (Urk. IV, 138.10). Los fenicios se llamaban a sí mismos kn'ny, mientras que sus vecinos hebreos los denominaban kana'ani.

2 Aubet 2006, 43-44.

3 Álvarez - Ferrer 2009, 191.

4 Arteaga et al. 2008, 73-76.

5 Arteaga et al. 2008, 52.

6 Véase Arteaga et al., 2001, 358, 412. 
con amplios ámbitos de tierra firme de ambas islas erosionados a lo largo del tiempo, casi desaparecidos en torno al año 1000 d.C., entre ellos una península lanzada hacia Poniente, perteneciente a la isla menor, que pudo extenderse al menos hasta la Punta de Rota, y otra aún más larga, situada al sur de la anterior, perteneciente a la isla mayor, que pudo llegar al menos hasta la Punta de la Muerte. El islote del castillo de San Sebastián es el resto más importante de esta última península, la meridional. Por lo que se refiere a la unión entre ambas islas, coincide en parte con la actual estrecha franja de terreno que se extiende, grosso modo, entre la calle José Celestino Mutis y la playa de la Caleta. El resto del istmo, quizá en torno a la mitad del total, es también dominio marítimo. El lugar arqueológico de la calle Paraguay ${ }^{7}$ estaría aproximadamente en la vertical del límite oriental de la lengua de tierra que unía ambas islas, pero en terrenos de la antigua isla mayor.

El resultado final de la unión de las cuatro antiguas islas puede compararse a una "Y" cuyo brazo izquierdo era más largo y más estrecho que el derecho. Llamaré simplemente 'isla gaditana' a esta unidad insular. El islote de Sancti Petri quedaba al sur de esta isla y separado de ella. ${ }^{8}$

Sabemos que los fenicios levantaron una serie de construcciones en el extremo del brazo occidental de esta isla. El primer aspecto que voy a abordar es el nombre que los fenicios pudieron dar a estas instalaciones.

\section{Arqueología y Paleotoponimia fenicio-púnica: Gadir}

Es un lugar común llamar Gadir (/'ga dir/) a las instalaciones levantadas por los fenicios en la zona norte de la isla gaditana porque hay un par de fuentes de época romana, en concreto Plinio el Viejo y Avieno, que utilizan este término para referirse a una entidad poblacional que podemos identificar con la ciudad que los romanos llamaron Gades. Plinio el Viejo afirma que los púnicos (poeni) llamaban Gadir a la isla que los mismos romanos llamaban Tarteson y otros Cotinusa, pues había otra isla, en la que, según el naturalista, estuvo antes la ciudad de Gades. ${ }^{9}$ Es decir, Plinio el Viejo establece la continuidad toponímica Gadir $\rightarrow$ Gades, aunque no topográfica, pues según el naturalista hubo una Gadir en una isla y después otra en una segunda isla. Por su parte, Avieno llama Gadir a una ciudad (urbs, oppidum) que identifica con Tartesus ${ }^{10}$ y a una isla que en principio se llamaba Cotinussa, aunque, según el poeta, fueron los colonos tirios quienes la llamaron Tartesus. ${ }^{11}$ Centrémonos en el topónimo Gadir.

Plinio el Viejo explicita que gadir, en lingua punica, significa «saepes», ${ }^{12}$ traducible por 'seto', ${ }^{13}$ 'cerca' o 'vallado'. Por su parte, Avieno indica, en su Ora marítima,

7 De Frutos - Muñoz 2004, 95.

8 Arteaga et al. 2008, 49-51, 69.

9 Plin., NH., 4.120.

10 Avien., Ora, 85-86, 267-269.

11 Avien., Orb., 615-616; Ora, 85-86, 267-269.

12 Plin., NH., 4.120.

13 THA IIB, 711, traducción de I. Illán. 
que gadir significa «locus conseptus» en la lingua punicorum, ${ }^{14}$ frase que se ha traducido por 'lugar cercado' ${ }^{15}$ y 'lugar vallado', ${ }^{16}$ mientras que, en su Descriptio orbis terrae, aduce que los púnicos llaman gadir a todo «locus saeptus aggere praeducto», ${ }^{17}$ que se ha traducido por 'lugar cerrado por los lados y un dique de tierra levantado delante' ${ }^{18}$ y por 'paraje rodeado completamente por un malecón delantero'. ${ }^{19}$

J. Sanmartín argumenta que la base /g-d-r/ que presenta el topónimo Gadir no está atestiguada como lexema autónomo en fenopúnico, de modo que la traducción tradicional por 'muro', 'recinto', 'seto', etc., se basa en la probable isoglosa con el hebreo $g d r(/ \mathrm{g} \bar{a} \mathrm{~d} \bar{e} \mathrm{r} /)^{20}{ }^{20}$ En efecto, en Palestina se documentan topónimos como Geder

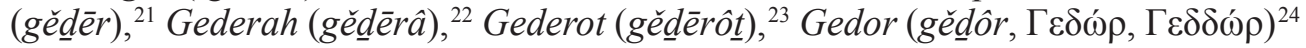
y Gadara $(\Gamma \alpha \dot{\alpha} \delta \alpha \alpha)^{25}$ que presumiblemente se corresponden con centros fortificados. ${ }^{26} \mathrm{G}$. Garbini, quien sostiene que Gadir fue una fundación filistea, ${ }^{27}$ defiende que ha-gader es un topónimo típicamente filisteo ${ }^{28}$ aunque no aclara si perteneciente a la lengua hablada por este pueblo durante su estancia en Creta o a la hablada en el siglo XI a.C. en Palestina, cuando, como el mismo G. Garbini destaca, los documentos filisteos aparecen redactados en escritura y lengua fenicias, indicio de que los filisteos habían abandonado bien pronto su escritura y adoptado la fenicia, haciendo poco después lo mismo con la lengua. ${ }^{29}$ Otros especialistas relacionan estos topónimos con la base trilítera semítica /g-d-r/ ('pared, muro, muralla, montón de piedras', etc.), ${ }^{30}$ también documentada en el extremo occidental del área de difusión de la macrofamilia de lenguas afroasiáticas, en concreto en la lengua bereber, en la que la realización agādìr tiene el significado general de 'fortaleza' ('granero comunitario fortificado, ciudad amurallada'). ${ }^{31}$ Según lo atestigua el topónimo Gadir $(g d r)$, también docu-

14 Avien., Ora, 268-269.

15 THA I, 88, traducción de P. Villalba i Varneda.

16 Calderón 2001, 318.

17 Avien., Orb., 615-616.

18 THA I, 191, traducción de P. Villalba i Varneda.

19 CALderón 2001, 228-229.

20 SANMARTín 1994, 234-235.

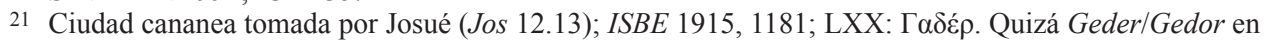
$1 \mathrm{Cr} 4.39$, aunque en $L X X$ : Гह́ $\rho \alpha \rho \alpha$.

22 Jos 15.36; $1 C r 4.23$ (en la versión revisada inglesa y americana); ISBE 1915, 1181: 'lugar cercado'. Gederotayim (heb. gédèrôtayim), 'lugar de recintos', también citado en Jos 15.36, según ISBE 1915, 1182, puede ser una ditografía del precedente Gederah; $L X X: \Gamma \alpha ́ \delta \eta \rho \alpha$.

23 Jos 15.41, $L X X$ : $\Gamma \varepsilon \delta \delta \grave{\rho} \rho$; conquistada por los filisteos en época del rey Acaz, como se indica en $2 \mathrm{Cr}$

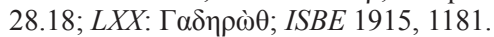

24 Jos 15. 58. Según ISBE 1915, 1182, parece que se refiere a ella Eusebio como Gadeira (Eus. Onom.,

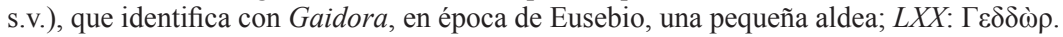

25 No es citada expresamente en la Biblia, pero en Mat. 8.28 se hace referencia indirecta a ella en $\chi \omega ́ \rho \alpha$ $\tau \tilde{\omega} v$ Г $\alpha \delta \alpha \rho \eta \tilde{\omega} v$; también en Marc., 5.2-10; J., AJ., 12.129, 12.305, etc., BJ., 1.86, 1.155, 1.167, etc., Vit., 32, 43, etc.; Plb., 16.39; Str., 16.2; Suet., Tib., 57; Plin., NH., 5.16, 35.58; véase Freedman 2000, 475.

26 Véase también para todos estos topónimos ANDERSON - Forbes 1990, 1379 GN, $138^{\circ}$ GN y 1352 GN y FreEdMAN 2000, 488.

27 GARBINI 1997, 123-126; ID. 1999, 163-164; ID. 2001, 42-43.

28 GARBINI 1999, 163.

29 Garbini 1997, 232-233.

30 CoHen et al. 1994, 120; EL , s.v. "Agadir",

31 NAÏT - Zerrad 2002, 734; $E L_{1}$ s.v. "Agadir"; $E L_{2}$, s.v. "Agadir" 
mentado como $h g d r$ y ' $g d r,{ }^{32}$ aunque finalmente no conservó ni el artículo he (ה) ni el álef ( $\mathrm{N}$ ) sustitutivo, la base /g-d-r/ también fue productiva en la lengua fenicia occidental. En opinión de J. Sanmartín, la paleotoponimia gaditana se relaciona con dos topónimos de raíz semítica, */'ga di rāa/ y /'ga dir/, pertenecientes a dos substratos lingüísticos y culturales emparentados pero distintos. El substrato más antiguo sería el responsable del híbrido fenoarameo */'ga di rā/, semántica y pragmáticamente

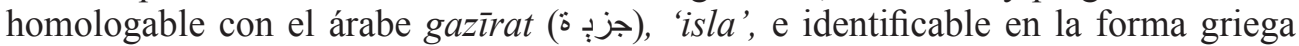
$\Gamma \alpha ́ \delta \varepsilon 1 \rho \alpha$, mientras el más tardío, de raíz púnica, representado por las variantes $h g d r$, ' $g d r$ y $g d r$, se remontaría a la etapa de predominio cartaginés, cuando el progresivo robustecimiento de las fortificaciones probablemente hicieron cambiar el sentido de 'isla' hacia el campo semántico de fortificación, convirtiendo */'ga di rāa/ en /'ga dir/. ${ }^{33}$ Debemos admitir que la hipótesis de J. Sanmartín está de acuerdo con la paleogeografía de la bahía de Cádiz, pues estamos hablando de una sola y única isla, cuyo nombre

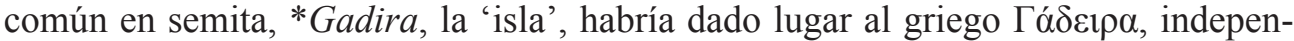
dientemente de que los eruditos griegos emplearan después el término como si fuera un nombre neutro en plural. Sin embargo, la erudición griega antigua también vincula la forma $\Gamma \alpha ́ \delta \varepsilon ı \rho \alpha$ con la idea de 'recinto', 'lugar cercado', etc., y no con la de 'isla',

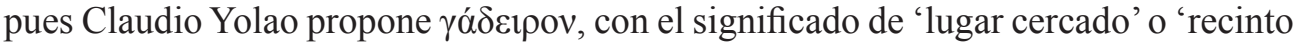
vallado', como el término fenicio para explicar el nombre de $\Gamma \alpha ́ \delta \varepsilon \iota \rho \alpha .{ }^{34}$ Hesiquio de

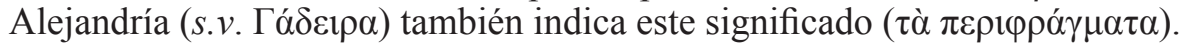

Si se opta por la interpretación del término $\Gamma \alpha ́ \delta \varepsilon t \rho \alpha$ como nombre neutro en plural es lícita su traducción, en la línea de Hesiquio de Alejandría, por 'las fortalezas', 'los recintos' o algo similar, pero queda excluida cualquier relación con la idea de 'islas'. Y ciudades amuralladas fenicias, que sepamos, había al menos dos en las cercanías de la isla gaditana: Castillo de Doña Blanca y cerro del Castillo de Chiclana. Si se interpreta el término $\Gamma \alpha ́ \delta \varepsilon \imath \rho \alpha$ como la forma griega de Gadir o de alguna de las realizaciones de la base /g-d-r/ que los griegos pudieron escuchar en el Mediterráneo oriental, repito, independientemente de que la literatura griega lo interpretara como un nombre neutro en plural, habría que pensar en su traducción como 'la fortaleza'. Yo me inclino por esta última opción. La transcripción del hebreo gizěrah, 'espacio cercado', nos ofrece las formas $\gamma \alpha \zeta \varepsilon \rho \alpha ́$ y $\gamma \alpha \dot{\zeta} \alpha \rho \alpha,{ }^{35}$ cercanas a la griega $\Gamma \alpha ́ \delta \varepsilon ı \rho \alpha .{ }^{36}$ Las Gederah y Gadara documentadas en Palestina nos ofrecen formas aún más próximas.

$\mathrm{El}$ inconveniente con el que nos topamos es que no se han hallado testimonios de sistema defensivo antiguo alguno en la actual península gaditana. ${ }^{37}$ Ante la imposibilidad de señalar un lugar claramente rodeado de alguna estructura defensiva en la isla gaditana, se ha interpretado el enclave como un "lugar cerrado" en sí mismo,

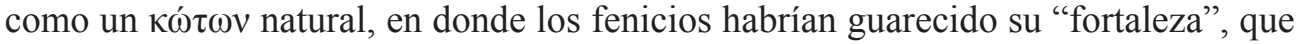

32 Filigheddu 2006, 166-167.

33 SANMARTín 1994, 234-235.

34 Claud. Iol., FGH 788 F 3.

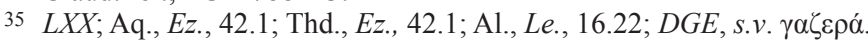

36 En los Scholia in Dionysii Periegesin, Гádeipa se traduce por «algo así como 'cuello de tierra'» (Scholia in D.P., 456: $\gamma \tilde{\eta} \varsigma \delta \varepsilon \iota \varphi \eta)$, mientras el Etymologicum Magnum lo interpreta como saliente o prominencia de la tierra (EM., 219.32G: $\tau \tilde{\eta} \varsigma \gamma \tilde{\eta} \varsigma \dot{\varepsilon} \xi o \chi \tilde{\eta})$, versión que amplía las posibilidades de ubicación de lugar.

37 Ruiz Mata 1999, 299. 
no sería sino el puerto interior existente en la ensenada que miraba a Levante. ${ }^{38}$ En cualquier caso, parece que el nombre que se atribuye a las estructuras levantadas en la isla gaditana durante época arcaica no se corresponden sensu stricto con lo que la Arqueología puede atestiguar, frente a las magníficas murallas documentadas, como acabo de indicar, en el Castillo de Doña Blanca y en el cerro del Castillo de Chiclana.

La construcción de la muralla arcaica del Castillo de Doña Blanca ha sido situada en el siglo VIII y su final en el VI a.C., ${ }^{39}$ documentándose además murallas de los siglos V-IV a.C. y del siglo III a.C., cuya edificación, en el caso de la última, implicó la destrucción de una buena cantidad de estructuras urbanas. ${ }^{40}$ Por lo que respecta a las del cerro del Castillo de Chiclana, según P. Bueno, A. García Menárguez y F. Prados, se documenta una primera fase que se extiende entre el momento en el que se construye el asentamiento y sus defensas, en los años finales del siglo IX o los iniciales del siglo VIII, ${ }^{41}$ y los años centrales del VII a.C., respondiendo su construcción a un diseño en el que la muralla se integra perfectamente con las edificaciones del interior, llegando a constituir la parte trasera de algunas estancias. ${ }^{42}$ Sin embargo, esta cronología no parece demasiado segura, pues A. García Menárguez y F. Prados admiten en un trabajo posterior que estas defensas «pudieron ser erigidas ya en el siglo VIII a.C.»,${ }^{43}$ no que efectivamente lo fueran.

Cuando los griegos comienzan a hablar, en la primera mitad del siglo V a.C., de una población que podemos identificar como el antecedente directo de la Gades de época romana, las fuentes helenas utilizan el término $\Gamma \alpha ́ \delta \varepsilon 1 \rho \alpha$, mientras, si damos crédito a Plinio el Viejo y Avieno, los púnicos la llamaban Gadir. Pero de este hecho no se deduce necesariamente que Gadir fuera el nombre de las instalaciones fenicias levantadas tiempo atrás en la isla gaditana. Sabemos que los topónimos cambian de lugar por diversas razones, de modo que otro enclave pudo portar este nombre en época arcaica, es decir, con anterioridad al siglo V a.C. Como ha defendido D. Ruiz Mata, un lugar que presenta magníficas condiciones para responder a las exigidas por el significado del término gadir es sin duda el establecimiento del castillo de Doña Blanca. ${ }^{44}$ Pero, Doña Blanca no es la única opción. En resumen, cabe la posibilidad de que alguna colonia fenicia fortificada levantada en la bahía de Cádiz recibiera el nombre de Gadir y de que el crecimiento poblacional de las instalaciones levantadas en la isla gaditana y el aumento de su importancia económica y política acabara por implicar el traslado del topónimo al lugar que adquirió el mayor peso específico

38 Arteaga et al. 2001, 380-383; Arteaga - Roos 2002, 26-32; Arteaga et al. 2008, 52.

39 Ruiz Mata 2001, 263-264; Escacena 2002, 73; Almagro-Gorbea - Torres 2007, 45; Prados - BlánQuez 2007, 63; RoDERO - BERROCAL-RANGEl 2011-2012, 229, 233.

40 Ruiz Mata 1998, 201-202; ID. 2001, 263-268.

41 Bueno et al. 2013, 35-36.

42 Bueno et al. 2013, 35-36. En opinión de López CAstro 2013, 517, la presencia fenicia en el Castillo de Doña Blanca, concebido como núcleo en tierra firme de Gadir para dominar las fértiles tierras de la ribera del Guadalete, se completaría con la proyección al Sureste de Gadir, mediante la fundación de un asentamiento fortificado coetáneo en el Castillo de Chiclana.

43 García Menárguez - Prados 2014, 120.

44 Ruiz Mata 1999. 
dentro de las instalaciones fenicias distribuidas por la bahía de Cádiz, esto es, el establecimiento finalmente conformado en la isla gaditana.

Las fuentes griegas y latinas también atribuyen otros nombres tanto a la isla gaditana como a otras islas supuestamente cercanas a la de $\Gamma \alpha ́ \delta \varepsilon 1 \rho \alpha$.

\section{Paleogeografía y Paleotoponimia greco-latina}

El mapa de las islas gadiritas que he comentado más arriba, un "archipiélago" realmente reducido a la isla gaditana y el islote de Sancti Petri, no se corresponde con el paisaje que podemos reconstruir a partir de las descripciones contenidas en las fuentes literarias greco-latinas, que, a su vez, mantienen marcadas diferencias entre sí en este sentido.

Diodoro Sículo hace hincapié en que el nombre de Гá $\delta \varepsilon \imath \rho \alpha$ se debía a que se levantó sobre una península, ${ }^{45}$ circunstancia que, como destaca G. Garbini, no se compadece con la insularidad que otras fuentes atribuyen al lugar en el que se fundó la "colonia", ${ }^{46}$ ni con la paleogeografía del territorio que estamos manejando. La descripción que debemos a Mela tampoco se corresponde con dicha reconstrucción paleogeográfica. El autor tingenterano indica que la isla de Gades era casi recta por la parte que daba a tierra firme, mientras que, por la parte que daba al Océano, poseía dos cabos que se adentraban en el mar, estando en una punta Gades, y en la otra el templo de Hércules ${ }^{47}$ En primer lugar, la isla era casi recta exactamente por la parte que daba al Océano y era precisamente su cara orientada hacia la bahía la que presentaba un corto y ancho saliente, con dirección Noreste, coincidente con la antigua isla de León. Tampoco queda clara la ubicación de la "ciudad" y del santuario que se le adjudica, pues puede interpretarse que estaban situados en los extremos de la isla -lo que no coincide con la propuesta actual de que el santuario de Melqart estaba en el islote de Sancti Petri, aún separado de la actual península gaditana- o en los extremos de ambos cabos. Pero la única forma de asumir que la parte casi recta de la isla era la que daba a tierra firme y que la isla de Sancti Petri era el segundo saliente que se adentraba en el mar es admitir que la isla de León/San Fernando no estaba unida a la isla de Cádiz-Campo Soto y que el islote de Sancti Petri sí estaba unido a esta última isla, como también parece deducirse de Estrabón.

En efecto, el geógrafo de Amasia indica que los tirios alzaron un santuario en la parte oriental de la isla y una ciudad en la occidental. ${ }^{48} \mathrm{~A}$ nadie se le escapa que esta orientación es imposible si se quiere vincular el santuario dedicado a Melqart, que la investigación ubica en el islote de Sancti Petri, ${ }^{49}$ con las construcciones levantadas en el Norte de la actual península gaditana. A. García Bellido defendía hace años

45 D.S., 5.20 .2 .

46 GARBINI 1999, 159.

47 Mela, 3.6.46.

48 Str., 3.5.5.

49 Según SÁEz et al. 2005, 875, el recinto sagrado estaría ubicado en la zona hoy cubierta por el mar entre el islote de Sancti Petri y la Punta del Boquerón. 
que este error fue consecuencia de haberse establecido la orientación en verano, estación durante la cual el sol parece salir y ponerse más por el Sur y más por el Norte, respectivamente, que en invierno, de manera que en Estrabón el Occidente es real-

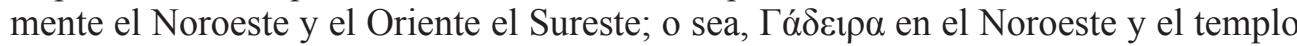
de Heracles en el Sureste. ${ }^{50}$ Esto podría quizá tener alguna validez si la visión de la orientación de la isla gaditana fuese similar a la actual, pero debe tenerse en cuenta que muy probablemente la visión antigua no coincide con la que hoy tenemos, una circunstancia que efectivamente ocurría con la Península Ibérica en su conjunto, pues este territorio se imaginaba en la Antigüedad girado muchos grados a favor de las agujas del reloj con respecto a la representación cartográfica actual, de forma que se pensaba que los Pirineos tenían una orientación Norte-Sur y que el río Ebro corría en la misma dirección. ${ }^{51}$

La isla de $\Gamma \alpha ́ \delta \varepsilon i \rho \alpha$ recibió algún que otro nombre por parte de la erudición grecoromana, como consecuencia de la integración de este espacio del Extremo Occidente en la mitología. En efecto, según Estrabón, parece que Ferécides de Atenas afirmaba

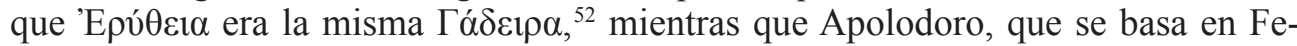
récides, confirma esta identificación. ${ }^{53}$ Es decir, la primera vez, que se sepa, que la literatura griega identificó $\Gamma \alpha ́ \delta \varepsilon ı \rho \alpha$ con 'E $v^{\prime} \theta \varepsilon \iota \alpha$, evento que sucedió a mediados del siglo $\mathrm{V}$ a.C., no hay indicios que insinúen la existencia de más de una isla. La ecua-

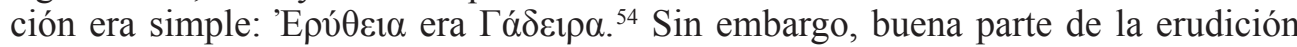
antigua asume la existencia de dos islas en lugar de una. En un caso, ambas islas reciben un único nombre. Así, en el periplo atribuido a Escílax de Caria, escrito que probablemente se remonta al siglo IV a.C., se da el nombre de $\Gamma \alpha ́ \delta \varepsilon 1 \rho \alpha$ a dos islas, una de las cuales, según el Periplus, tenía una ciudad. ${ }^{55}$ Pero, en los casos restantes, las islas reciben nombres distintos. Este es el caso de Heródoto, que sitúa 'Epú $\theta \varepsilon 1 \alpha$ en las proximidades de $\Gamma \alpha ́ \delta \varepsilon \iota \rho \alpha,{ }^{56}$ quizá no tan cerca como quieren otros escritores posteriores. En efecto, por Estrabón sabemos que algunos eruditos, que el geógrafo no nombra, afirmaban que Eritea se extendía paralela a la ciudad de $\Gamma \alpha ́ \delta \varepsilon 1 \rho \alpha$, pero separada de ella por un estrecho. ${ }^{57} \mathrm{Si}$ se pretende hacer coincidir dicho estrecho con el canal Bahía-Caleta, debe recordarse que la Paleogeografía de la zona documenta que este canal no existía desde antes de los inicios del I milenio a.C. Parece que la insularidad era un dato implícito en su identificación con la isla Eritea. Es decir, si era Eritea, tenía que ser una isla y no parte de una isla. Y si Eritea no era la isla de $\Gamma \alpha ́ \delta \varepsilon t \rho \alpha$, es obvio que tenía que haber otra, más o menos cercana. Pero Estrabón tam-

50 García Bellido 1968, 193

51 Str., 3.4.10.

52 Str., 3.5.4; Pherecyd., FGH 3 F $18 \mathrm{~b}$

53 Apollod., 2.5.10; véase THA I, 98-99; THA IIA, 71-72; THA IIB, 487-489, 551. Esteban de Bizancio, por

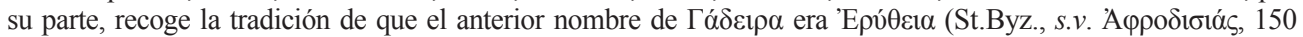
Meineke).

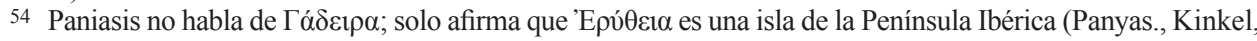
$E G F, 253)$.

55 Scyl., Per. 1 y 111.

56 Hdt., 4.8 .

57 Str., 3.5.4. Es probable que Estrabón estuviera pensando en la opinión de Éforo, que conocemos a través de Plinio el Viejo (Eph., FGH 70 F 129a; Plin., NH., 4.120); véase THA IIA, 167. 


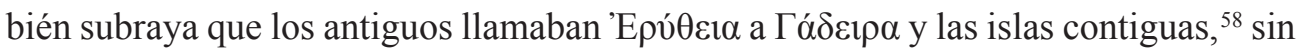
que tengamos una respuesta adecuada sobre qué islas contiguas eran esas que citaban los antiguos, salvo que se trata de un paisaje imaginado.

Por su parte, Plinio el Viejo asevera que Éforo y Filístides llamaban Erythea a una isla, en la que estuvo con anterioridad la población de Gades, que estaba situada entre la isla de Gades y el continente. ${ }^{59}$ De todas formas, debe subrayarse que el naturalista habla de dos islas y no de dos antiguas islas unidas por una ancha y corta lengua de tierra. Nos hallamos de nuevo ante la hipótesis dual. Ya he indicado que el mapa de las islas gadiritas restituido por la Paleogeografía no se corresponde con el paisaje que pretenden las fuentes literarias antiguas y esta cita del naturalista es un buen ejemplo, pues sabemos que no había isla alguna entre la isla gaditana y el continente.

Eritea, la 'roja', pertenece a la geografía mítica, pues, aunque es una de las Hespérides ${ }^{60}$ también es la isla en la que se desarrolla el mito de Gerión transmitido por Estesícoro y Apolodoro. ${ }^{61}$ En consecuencia, las distintas ubicaciones de Eritea no son sino distintos intentos de situar un mito en el espacio. Cuando le llegó el turno a la bahía de Cádiz, Eritea se identificó tanto con la isla gaditana, como con una isla imaginaria muy cercana a esta. No podemos afirmar que la identificación de Eritea

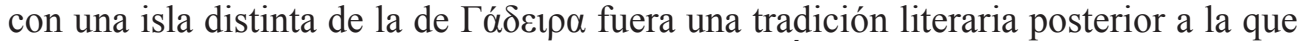
recoge Ferécides, a pesar de que los testimonios de Éforo y Filístides son más tardíos, pues parece que estamos ante dos tradiciones distintas cuyos respectivos inicios no podemos documentar.

Plinio el Viejo también indica que Timeo y Sileno llamaban Aphrodisias a Eritea, ${ }^{62}$ que también se ha identificado con la Veneris Marinae insula, en la que, según Avieno, se hallaba el templo de Venus. ${ }^{63}$ Estamos pues ante una helenización toponímica concretada en la sustitución de la referencia a Venus por un derivado de Afrodita, una diosa grecochipriota que los fenicios identificaban con Astarté y en la difusión de cuyo culto participaron los cananeos a lo largo de las rutas marítimas por ellos frecuentadas. ${ }^{64}$ Plinio el Viejo también indica que los "indígenas" denominaban Iunonis insula a Eritea, ${ }^{65}$ una afirmación que encaja perfectamente con los nombres anteriores, pues es probable que los enclaves de la región del estrecho de Gibraltar que las fuentes presentan como consagrados a Juno, lo estuvieran en realidad a As-

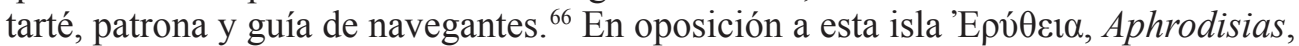
Veneris Marinae o Iunonis, las fuentes literarias greco-latinas llaman Cotinusa a una isla muy cercana a Eritea.

Plinio el Viejo afirma que los púnicos llamaban Gadir a la isla que los mismos romanos llamaban Tarteson y otros Cotinusa, que era distinta de aquella en la que,

58 Str., 3.2.11.

59 Plin., NH., 4.120; Eph., FGH 70 F 129a; Philistid., FGH 11 F 3.

60 Hes., Fr. 360; Apollod., 2.5.11.

61 Stesich., PMGF, 154 (= Str., 3.2.11; 7 SLG), 87 SLG; Apollod., 1.6.1; 2.5.10.

62 Plin., NH., 4.120; Timae., FGH 566 F 67; Silen., FGH 175 F 7.

63 Avien., Ora, 314-316.

64 VALDÉS 2013.

65 Plin., NH., 4.120.

66 Marín 2011, 217. 
según el naturalista, estuvo antes la ciudad de Gades. ${ }^{67}$ La isla llamada Tarteson/ Cotinusa, según parece, era ostensiblemente mayor que aquella en la que se supone estuvo antes Gades, dadas las medidas que Plinio el Viejo atribuye a cada una. Plinio el Viejo señala que, según Timeo, la isla era denominada Cotinusa por sus

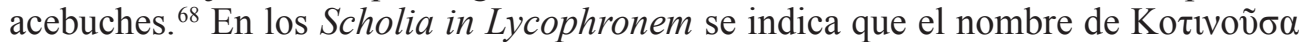
era anterior al de $\Gamma \alpha ́ \delta \varepsilon \imath \rho \alpha,{ }^{69}$ afirmación que es seguida por Dionisio Periegeta, pues

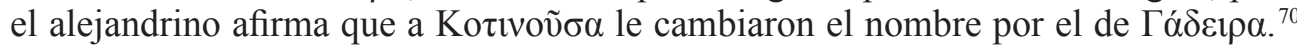

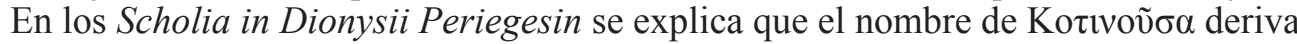

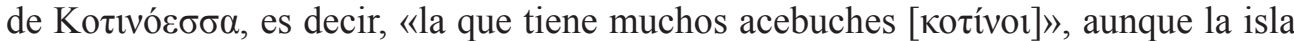
cambió su nombre por el de $\Gamma \alpha ́ \delta \varepsilon 1 \rho \alpha .^{71}$ La referencia a los acebuches no es un simple dato florístico. Como F. López Pardo destaca, los acebuches debieron de representar un papel muy significativo desde el punto de vista simbólico en los momentos fundacionales de las colonias fenicias, de manera que la "isla de los olivos silvestres" parece tener conexiones tanto con Melqart y Tiro, como con el acto fundacional de una colonia. ${ }^{72}$ Es decir, parte de la erudición antigua atribuye a una isla un nombre,

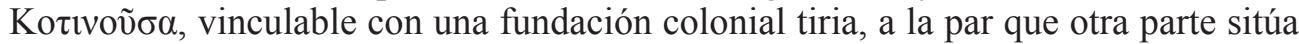
una colonia tiria en otra isla, a la que llaman 'E $\rho$ v́ $\varepsilon 1 \alpha$ y Aphrodisias y que estaba consagrada a Venus Marina y a Juno. O estamos ante una isla y una "colonia", o ante dos islas y dos "colonias". La primera premisa me parece mucho más aceptable que la segunda por razones paleogeográficas y arqueológicas. Quizá sea mera coincidencia, pero Avieno llama Gadir, Tartesus y Cotinussa a la misma isla ${ }^{73}$ y no habla de otra u otras cercanas.

Por otra parte, todas las fuentes helenas antiguas que tratan del tema proponen

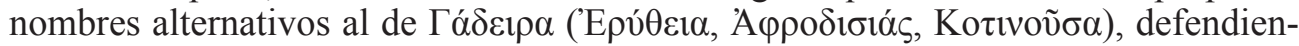

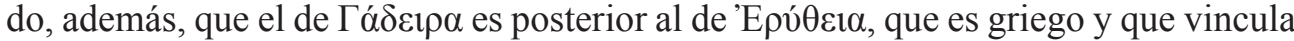
a la isla con la mitología griega, y al de Kotıvoṽ $\alpha$, que es griego y que vincula la isla con las navegaciones eubeas, circunstancias que permiten imaginar un interés heleno, especialmente eubeo, en reivindicar la primacía de las actividades marineras por estos contornos, supuestamente anteriores a las fenicias. ${ }^{74}$

Es obvio que los autores antiguos no coinciden entre sí a la hora de describir el escenario de las supuestas islas gadiritas, su número, sus formas, su distribución y su ubicación, ni a la hora de situar la población y el santuario de Melqart que se supone estaba levantado en el islote de Sancti Petri y vinculado al establecimiento situado en el extremo del brazo occidental de la isla gaditana desde sus orígenes. La sensación general es que estas referencias son creaciones literarias con bases geográficas poco reales, por puro desconocimiento, pero suficientes para construir un escenario creíble desde el punto de vista literario, cuya adecuación a la realidad difícilmente iba a ser

67 Plin., NH., 4.120.

68 Plin., NH., 4.120; Timae., FGH 566 F 67.

69 Scholia in Lyc., Alex., 649.

70 D.P., 456.

71 Scholia in D.P., 456. En el siglo XII, Eust., Comm. in D.P., 451, reproducía literalmente la cita.

72 LÓPEZ PARdo 2004, 22.

73 Avien., Ora, 85-86, 267-269; Orb., 615-616; Ora, 85-86, 267-269.

74 López PARdo 2004, 21. 
comprobada. En el caso de aquellos escritores que pudieron haber bebido de Posidonio, que visitó Gades, parece que no entendieron bien lo que el geógrafo de Apamea pudo decir respecto del paisaje de la bahía o simplemente este no hizo tal descripción. Las contradicciones que las fuentes literarias mantienen entre sí abogan por la mayor fiabilidad del paradigma paleogeográfico expuesto.

De hecho, la Arqueología acredita que las construcciones fenicias más antiguas se levantaron al norte de la línea imaginaria definida por el entonces ya parcialmente cegado canal Bahía-Caleta, en un espacio en el que hoy se encuentran la Torre de Tavira y sus alrededores, las calles San Miguel (Cine Cómico) y probablemente la calle Solano, ${ }^{75}$ pero también al sur de dicha línea, en el área limitada por la parroquia de Santa Cruz (la "catedral vieja") y la actual catedral, situada en un pequeño promontorio cercano a la orilla meridional de la ensenada interior, en donde se ha documentado una secuencia estratigráfica de los siglos VIII y VII a.C. ${ }^{76}$ En resumen, no puede hablarse de una Gadir vieja en una isla y una nueva en otra isla, como pretenden algunas fuentes literarias. El proceso de crecimiento poblacional se desarrolló en un único escenario insular.

\section{Cronología, Literatura y Arqueología}

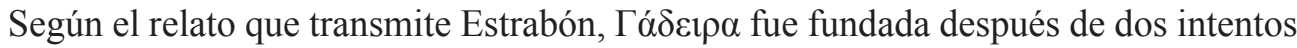
previos fracasados ${ }^{77} \mathrm{y}$, de acuerdo con Diodoro Sículo, $\Gamma \alpha ́ \delta \varepsilon \varphi \rho \alpha$ fue la primera ciudad fundada por los fenicios más allá de las Columnas de Heracles. Ninguno de los dos afirma que fuera la fundación tiria más antigua en Iberia. ${ }^{78}$

La leyenda de la que se hace eco Estrabón, probablemente recogida por Posidonio en la misma Gades en el paso del siglo II al I a.C., sostiene que, después del intento de fundar un establecimiento en 'E $\xi$ (identificable con Sexi-Almuñécar), rechazado por los dioses, se produjo una segunda tentativa en una isla consagrada a Heracles cercana a 'Ovó $\beta \alpha$, habitualmente identificada con la isla de Saltés, que tampoco recibió la correspondiente bendición de la divinidad. En la tercera expedición, cuenta el relato, los tirios fundaron $\Gamma \alpha ́ \delta \varepsilon \iota \rho \alpha$ y alzaron un santuario en la parte oriental de la isla. ${ }^{79}$ Este pasaje transmitido por Estrabón suele interpretarse como un reflejo de las exploraciones previas a la fundación de una colonia en la isla en la que por entonces se levantaba Gades. Quiero subrayar el hecho de que fueron dos, y no más, los intentos previos, que sumados al de la fundación nos dan el número tres.

G. Cruz Andreotti destaca que el modelo fundacional utilizado en la narración incluye los elementos habituales, es decir, el mandato oracular, el mito de precedencia -en este caso el viaje de Melqart-, los sacrificios para conocer la opinión de la divinidad acerca de la decisión humana y, por último, la consagración del lugar

\footnotetext{
75 Córdoba - Ruiz Mata 2005; De Frutos - Muñoz 2008, 243.

76 Perea et al. 2004, 232.

77 Str., 3.5.5.

78 D.S., 5.20.2.

79 Str., 3.5.5.
} 
al héroe protector, en esta ocasión la divinidad tutelar de Tiro, Melqart, ${ }^{80} \mathrm{o}$ incluso Milq aštart, ${ }^{81}$ con la elevación del templo correspondiente. Pero, además, la narración era la típica leyenda de idoneidad que reafirmaba etnocéntricamente la idea de los habitantes de Gadir de hallarse en el mejor de los lugares posibles, ${ }^{82}$ que los convertía en los únicos herederos del dominio que les había concedido Melqart ${ }^{83}$ y que otorgaba a la fundación de la ciudad el carácter de acto perfecto, pues esta se produjo al tercer intento, que es la idea que subyace al proverbio "a la tercera va la vencida" y a otros similares basados en el tres, bien difundidos en el Mediterráneo antiguo, número que encierra el símbolo de la perfección, por lo que su aplicación transmite el alcance perfecto de toda acción. ${ }^{84}$

El texto se ha entendido, pienso que adecuadamente, como una manifestación de los intereses de la oligarquía gadirita, animada por el objetivo de demostrar la mayor antigüedad de Gadir frente a las otras dos ciudades citadas en el pasaje, Sexi y Ono$b a$, que muy presumiblemente disputaban a Gadir la prestigiosa primacía de su fundación con antiguas leyendas propias que desconocemos. ${ }^{85}$ Aunque no se explicita de manera inequívoca en ninguna fuente, quizá lo que se dilucidaba en esta polémica, en el caso de que efectivamente hubiera surgido, era el puesto de primera colonia tiria en el Occidente.

A pesar de lo afirmado por Diodoro Sículo, según la Arqueología, el primer establecimiento fundado por los fenicios más allá del estrecho de Gibraltar-Columnas de Heracles no se produjo en la bahía de Cádiz, sino que se levantó en terrenos hoy ocupados por el casco urbano de Huelva. ${ }^{86}$ La cronología atribuida al conjunto cerámico fenicio hallado en el solar que se extiende por las fincas números del 7 al 13 de la calle Méndez Núñez y 12 de la plaza de Las Monjas lo sitúa entre 900 y 770 a.C.. ${ }^{87}$ pero la fundación del establecimiento puede ubicarse preferentemente en el segundo cuarto del siglo IX a.C. El asentamiento en este lugar fue resultado de la política de

80 CRuz Andreotti 1994, 74.

81 Esta divinidad, documentada en Gadir en el siglo II a.C. (ICO, Spagna 12) y que aparece en algún que otro lugar como idéntico a Melqart, ya que ambos se identifican con Heracles (MARín 2011, 218-219), ha sido reconocida por TsiRkin $(2007,167-178)$ detrás de la figura de Arcaleo, personaje que, según Claudio Yolao,

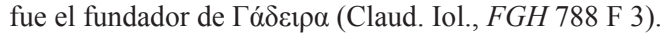

82 ZAMORA 2006, 361.

83 LÓPEZ PARdo 2004, 25.

84 Dagmar 1996, 64; Benítez 2009, 93. En opinión de Ribichini 2000, 663, 666, el análisis mitológico confirma la presencia de una inspiración griega en la narración estraboniana que hace difícil reconstruir una hipotética tradición fenicia en la que eventualmente pudo basarse la narración y la (re)elaboración gadirita, pues, aunque podemos reconocer algunos elementos, como el origen tirio de los fundadores, el carácter oficial de la empresa y el preeminente papel concedido al oráculo de Melqart, la inspiración griega del mito hace efectivamente vano cualquier intento de reconocer la historia narrada en los acontecimientos y origina graves inconvenientes a aquellos que todavía quieren comparar estos datos con los arqueológicos.

85 Presedo 1981, 30-31; LóPez Pardo 2004, 25.

86 Véase Pellicer 1996, 128, quien defiende la existencia de dos núcleos diferentes, uno correspondiente a un establecimiento indígena y el otro a un asentamiento fenicio, y GonZÁlez DE CANALES et al. 2004; ID. 2006; ID. 2006a; ID. 2008; ID. 2008a; ID. 2009; ID. 2010, que sostienen la existencia de una etapa "emporitana-precolonial", que se extendería desde 900 a 770/740 a.C., seguida de otra colonial propiamente dicha o "emporitana-colonial".

87 GonzÁlez de Canales et al. 2006, 13. 
expansión colonial fenicia en dirección occidental iniciada por el rey Ittobaal I (887856 a.C.) de Tiro ${ }^{88}$ la cronología de cuyo reinado coincide con la primera mitad de la fase mejor representada en el contexto cerámico fenicio de Méndez Núñez-Las Monjas, paralela a Tiro 7-6, situable aproximadamente entre 875 y 825 a.C. ${ }^{89}$ y con el inicio de la presión asiria, en época de Asurnasirpal II (883-859 a.C.), durante cuyo reinado Tiro es mencionada por primera vez como tributaria de los asirios. ${ }^{90}$

Un par de eruditos antiguos ofrecen fechas concretas para la fundación de Gadir y del templo de Heracles con el que se la vincula. Se trata de Veleyo Patérculo y Mela. Veleyo Patérculo sitúa la fundación de Gades ochenta años después de la conquista de Troya y ciento veinte años después de la apoteosis de Hércules, ${ }^{91}$ entre otros eventos "históricos", mientras que Pomponio Mela ubica la fundación del templo de Hércules por la misma época que la guerra de Troya. ${ }^{92}$ Por su parte, Estrabón sitúa

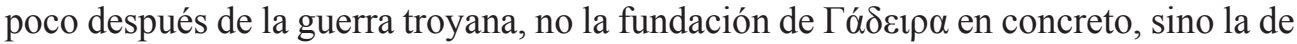
ciudades fenicias más allá de las Columnas de Heracles. ${ }^{93}$

Por lo que respecta al texto de Veleyo Patérculo, opino que las apreciaciones de A. J. Domínguez Monedero sobre este asunto son muy pertinentes, pues este autor destaca que resulta inadecuado seguir insistiendo en la cronología que se desprende de la obra del historiador campano como si fuera una verdad absoluta, vista la naturaleza problemática desde el punto de vista histórico de los sucesos supuestamente ocurridos a la vez que la fundación de Gades, que resultaría ser el único acontecimiento auténtico dentro de un conjunto de hechos (el retorno de los Heráclidas, la muerte de Codro y el ascenso al arcontado de Medonte) cuya historicidad es más que dudosa, o de un dato (como la cronología de la fundación de Mégara) cuya adecuación a la realidad histórica es más que deficiente, todo ello rematado por el empleo de la elevación de Hércules a la categoría de dios como segundo referente cronológico. ${ }^{94}$ Según la cronología utilizada por Veleyo Patérculo, la fundación de Gades habría tenido lugar hacia 1110 a.C. Pero no es esta la única fecha posible, ni la más antigua, pues, como destaca M. Pellicer, según Heródoto la guerra de Troya acaeció más de ochocientos años antes de su tiempo, ${ }^{95}$ por lo que si el historiador de Halicarnaso escribió hacia mediados del siglo V a.C., la destrucción de Troya habría ocurrido a mediados del siglo XIII a.C. y, en consecuencia, siguiendo a Veleyo Patérculo, Gadir se habría fundado en el segundo cuarto del siglo XII a.C., o quizá en el primero, ${ }^{96}$ esto es, en torno a 1175 a.C., solución que eleva aún más la cronología, que se remonta a 1190 a.C. en el caso de la fundación del santuario de Melqart, si seguimos a Mela. ${ }^{97}$

88 Aubet 2009, 228.

89 Mederos - Ruiz Cabrero 2006.

90 Carayon 2008, 60.

91 Vell. Pat., 1.2.3.

92 Mela, 3.6.46.

93 Str., 1.3.2.

94 Domínguez Monedero 2012, 167-168.

95 Hdt., 2.145.

96 Pellicer 2006, 101.

97 Los especialistas partidarios de las dataciones más altas tienen una magnífica ocasión de seguir elevándolas si asumen las propuestas de Giannakos 2013, 431, quien defiende que la guerra de Troya pudo ser más antigua que lo que indica la cronología tradicional, pues pudo desarrollarse entre 1425 y 1370 a.C. 
Como sostiene S. Ribichini, la fundación de Gadir se sitúa, en las fuentes, en una dimensión geográfica y temporal que puede definirse sin problemas como mítica, interpretando en este sentido también los testimonios que hablan de la fundación como de un hecho histórico. ${ }^{98}$ Estimo innecesario destacar el evidente desacuerdo que existe entre las fechas que manejan estos dos eruditos antiguos y la Arqueología, circunstancia que ha sido puesta de manifiesto por la investigación en múltiples ocasiones, pero entiendo que es preciso subrayar la falta de adecuación de las narraciones de ambos a la Historia de los fenicios en el Mediterráneo oriental.

Como sugiere C. G. Wagner, las causas de la expansión mediterráneo-atlántica de los fenicios no hay que buscarlas ni exclusiva ni fundamentalmente en los intereses comerciales, sino en las condiciones internas de las propias ciudades de Fenicia, enfrentadas a graves problemas, entre ellos un fuerte desarrollo demográfico de difícil solución mediante la expansión territorial por el entorno, ${ }^{99}$ dificultades crecientemente agudizadas por la presión ejercida por los reyes asirios. El acoso asirio se había iniciado, como vimos, con Asurnasirpal II y fue eficazmente continuado por Salmanasar III (858-824 a.C.). La presión tuvo que ser lo suficientemente grave como para provocar la diáspora mediterránea fenicia, iniciada durante el reinado de Ittobaal I, entre otras consecuencias. El hostigamiento asirio se acentuó durante el tercer cuarto del siglo IX a.C., como resultado de las campañas realizadas por Salmanasar III, que coinciden con la segunda mitad de la fase mejor representada en el contexto cerámico fenicio de Méndez Núñez-Las Monjas. Durante el reinado de este soberano, se desarrolló la primera verdadera guerra entre Asiria y los fenicios, que culminó en la batalla de Qarqar (853 a.C.), en la que varias ciudades-estado fenicias se aliaron frente al ejército de Salmanasar III, ${ }^{100}$ batalla que puede ser considerada el definitivo punto de inflexión para algunas ciudades fenicias, ${ }^{101}$ entre ellas Tiro, que dio un mayor impulso a su política colonial en el Mediterráneo central-occidental y la costa ibérica oceánica. ${ }^{102}$

La presencia tiria en la bahía de Cádiz pudo iniciarse en el paso del siglo IX al VIII a.C., según los materiales hallados en el llamado "puerto interior" 103 y el solar de la calle San Miguel en el que se levantó el Cine Cómico, ${ }^{104}$ instalaciones que probablemente se alzaron al mismo tiempo que se producía la fundación de la colonia del castillo de Doña Blanca, un asentamiento amurallado de gran tamaño cuyos inicios son situables en torno a 800 a.C. ${ }^{105}$ como mínimo, tal vez como resultado de alguna de las expediciones enviadas desde la metrópolis tiria, aunque, en opinión de J. Ramón,

98 RIBICHINI 2000, 665-666.

99 WAGNER 2000, 85.

$100 A R A B$ I, $\$ 611$.

101 Hodos 2011, 23.

102 Como sostiene Ferrer 2010, 74, no puede afirmarse taxativamente que Tiro fuera el protagonista exclusivo del proceso colonizador, pues algunas ciudades de la costa sirio-palestina y de Chipre pudieron participar, pero parece que debemos atribuir a Tiro el protagonismo en dicho proceso.

103 Arteaga et al. 2001, 391; Arteaga - Roos 2002, 26, 31: «utilización portuaria de este fondeadero interior, por parte de los barcos fenicios, alrededor del siglo IX-VIII a.C. cuando menos».

104 GENER et al. 2012, 179-180: «Dichos niveles se fechan en la actualidad en la primera mitad del siglo VIII a.C. utilizando la cronología convencional y a caballo entre los siglos IX-VIII a.C. usando la calibrada».

105 ZAMORA 2006, 359. 
ciertos datos arqueológicos permiten plantear la posibilidad de que la llegada de los cananeos a la bahía de Cádiz pudo producirse desde bases fenicias ya previamente consolidadas en la costa de Málaga. ${ }^{106}$ Por su parte, los hallazgos de la calle Cánovas del Castillo parecen pertenecer a un establecimiento, también aparecido en el paso del siglo IX al VIII a.C., de escasa duración temporal, relacionado con la pesca del atún y su posterior procesado, que únicamente se ocupaba en la época de capturas. ${ }^{107}$ Los editores de los hallazgos subrayan que las notables diferencias existentes entre los materiales coetáneos de Cánovas del Castillo y los de Doña Blanca inducen a pensar en orígenes distintos para ambas instalaciones, no siendo improbable el origen sardo o centromediterráneo de los fenicios de Cánovas del Castillo. ${ }^{108}$ Esto último puede ser una hipótesis razonable en cuanto plantea la posibilidad de que atuneros fenicios previamente establecidos en Cerdeña se instalaran en una factoría en la isla gaditana, al rebufo del asentamiento de sus hermanos en la colonia del castillo de Doña Blanca y en la misma isla.

\section{Un sitio para los dioses y los atuneros}

Las estructuras levantadas durante los siglos VIII-VII a.C. en la parte septentrional de la actual península de Cádiz no parece que correspondieran a una gran ciudad vertebradora de la colonización fenicia del Extremo Occidente. ${ }^{109}$ De hecho, no puede demostrarse fehacientemente siquiera la existencia de un asentamiento permanente de gran envergadura. Cierto es que las excavaciones arqueológicas realizadas en la calle San Miguel, en el lugar en el que se levantó el Cine Cómico, han sacado a la luz una secuencia estratigráfica ininterrumpida que ha proporcionado restos de un asentamiento que muestra un trazado en el que se pueden distinguir edificios construidos con técnicas típicamente orientales. ${ }^{110}$ Estas construcciones han suministrado evidencias de actividades administrativas (bullae) muy antiguas, pues se fechan en el paso del siglo IX al VIII a.C., frente al resto de los documentados en el Mediterráneo central y occidental, que se sitúan desde el siglo VI a.C. en adelante. ${ }^{111}$ Según los editores de los hallazgos, el escaso número de sellos hallados en el lugar sugiere que los documentos pertenecían a un particular, pudiéndose además plantear hipotéticamente el carácter comercial de los mismos, ${ }^{112}$ ninguno de los cuales, por cierto, se hizo en la bahía de Cádiz, pues llegaron custodiando sus respectivos documentos, dado el contenido fósil y parte de la mineralogía de la arcilla empleada en su elaboración, desde el Norte de África o desde el Mediterráneo oriental. ${ }^{113}$ Desestimar la pertenencia de dichas bullae a un contexto cultual, circunstancia por otra parte habitual en el Medi-

\footnotetext{
106 RAMÓN 2006.

107 Córdoba - Ruiz Mata 2005, 1316-1317.

108 Córdoba - Ruiz Mata 2005, 1312.

109 RAMÓN 2006.

110 GENER et al. 2012, 179.

111 GENER et al. 2012, 177

112 Gener et al. 2012, 178.

113 Gener et al. 2012, 180.
} 
terráneo, no puede basarse en criterios cuantitativos en este caso, dada la aleatoriedad de los hallazgos arqueológicos. La lejanía de las edificaciones de la finca del Cine Cómico de la presumible ubicación de cualquiera de los santuarios cuya presencia en la isla gaditana podemos suponer es sin duda un argumento de mayor peso. No rechazo en absoluto las propuestas de los editores de los hallazgos, porque son sensatas y perfectamente plausibles. Únicamente planteo que no se ha publicado dato alguno de este contexto que excluya definitivamente la posibilidad de que estemos ante un edificio religioso o al menos dependiente de una construcción de esta categoría y de que algunos indicios hacen razonable una propuesta alternativa no excluyente. Así, entre los restos de los dos edificios correspondientes al Periodo IV, situable en el segundo y tercer cuarto del siglo VI a.C., destaca un umbral con pavimento de conchas de diferentes especies, ${ }^{114}$ que nos podría remitir a la existencia de un ambiente eminentemente cultual durante dicho siglo. ${ }^{115}$ Cabe la posibilidad de que en siglos anteriores también fuera así. El arrasamiento de las estructuras correspondientes al Periodo II (ca. 820/800-720 a.C.) y el desmantelamiento de las construcciones del Periodo III (desde fines del siglo VIII a inicios del VI a.C.) ${ }^{116}$ quizá acabaron con umbrales de similares características. Es más, en el edificio construido durante este último periodo se han podido distinguir, hasta el momento, cinco estancias, la mayor de las cuales es una sala rectangular con una superficie superior a 16.54 metros cuadrados con, según los excavadores, un pilar central de adobes y un banco corrido apoyado contra la pared del fondo de la misma. ${ }^{117} \mathrm{El}$ tamaño de la habitación, el banco corrido en el fondo de la misma ${ }^{118} \mathrm{y}$ el pilar de adobes, que puede ser interpretado como los restos de un altar central, ${ }^{119}$ hacen plausible la interpretación del edificio como un santuario, tal vez sustituto de otros anteriores, desaparecidos como consecuencia de sendos acontecimientos traumáticos bien documentados por los excavadores. ${ }^{120}$ Por su parte, las huellas de tres o más bóvidos (Bos taurus) que han quedado marcadas en el pavimento más antiguo del espacio abierto (calle) entre los dos grupos estructurales del Período II ${ }^{121}$ pueden ser intepretadas sensatamente como pertenecientes a bueyes que tiraban de un carro, pero también podemos pensar que corresponden a toros que, como víctimas sacrificiales, eran llevados al lugar de inmolación. La complejidad espacial, que puede ser razonablemente atribuída a un desarrollo urbanístico, también puede ser consecuencia de la existencia, en torno al espacio sagrado propiamente dicho, de numerosas estructuras interpretables como almacenes y áreas de servicio. ${ }^{122}$ La misma presencia de ánforas ${ }^{123}$ puede ser legítimamente relacionada con un consu-

114 ZAMORA et al. 2010, 210; GeNER et al. 2012, 139.

115 ESCACENA - VÁZQuEZ 2009.

116 ZAMORA et al. 2010, 206-210.

117 ZAMORA et al. 2010, 206; GeNer et al. 2012, 138.

118 Arruda - Celestino 2009, 40; Almagro-Gorbea et al. 2011-2012, 249.

119 Belén - Escacena 1997; Arruda - Celestino 2009, 40.

120 Zamora et al. 2010, 206-209; Gener et al. 2012, 138.

121 ZAMORA et al. 2010, 212; Gener et al. 2012, 143.

122 Fernández Flores - Rodríguez Azogue 2005.

123 De los nueve grafitos publicados por ZAMORA et al. 2010, 212-215, siete aparecieron en fragmentos de ánforas. 
mo profano, pero también puede vincularse con la celebración de rituales plenamente religiosos. ${ }^{124}$

Ciertamente, como indica la planimetría publicada, ${ }^{125}$ las estructuras constructivas se continúan por los cuatro perfiles de la excavación, lo que indica que el hábitat era más extenso, pero, aunque los resultados del sondeo de la finca número 13 de la calle del Marqués del Real Tesoro no fueron tan negativos como se ha publicado, ${ }^{126}$ desconocemos la extensión real de las edificaciones y si es razonable pensar que estas corresponden a un entramado urbano de buena envergadura, también es una inferencia plausible sostener que las estructuras del Cine Cómico pueden corresponder a un pequeño núcleo durante los siglos VIII-VII a.C.

Frente a las dudas que los hallazgos del Cine Cómico puedan plantear en cuanto a su extensión, la implantación urbana de gran extensión se documenta sin mayores problemas en el castillo de Doña Blanca, población que, dentro de la hipótesis de la especialización funcional de las distintas zonas de la bahía de Cádiz defendida por D. Ruiz Mata, sería el núcleo habitacional principal, mientras que la isla gaditana sería el escenario quizá no exclusivo pero sí prioritario de las actividades religiosas y, en algunos lugares, de tareas relacionadas con la pesca y el procesamiento de las capturas, probablemente en torno al "puerto interior", como documentan los hallazgos de la calle Cánovas del Castillo y de la finca del desaparecido Teatro Andalucía. ${ }^{127}$ Una especial vinculación entre las instalaciones de la isla gaditana y el establecimiento levantado en Doña Blanca podría inferirse de las semejanzas existentes entre las estructuras del solar del Cine Cómico y las áreas de habitación contemporáneas de Doña Blanca, ${ }^{128}$ el paralelismo existente entre el horno de pan documentado en el Cine Cómico y los conocidos en Doña Blanca ${ }^{129}$ y las similitudes gráficas evidenciadas, más allá de la mera correspondencia paleográfica a un mismo periodo, entre alguna inscripción de las exhumadas en la finca del Cine Cómico y algún grafito hallado en el yacimiento de Doña Blanca. ${ }^{130}$

\section{Santuarios}

Se desconocen los detalles concretos de las edificaciones consagradas a los dioses. Como se indicó más arriba, la "isla" Eritea se ha identificado con la Veneris Marinae insula, en la que, según Avieno, se hallaba el templo de Venus, cerca del cual se abría

124 Gracias a los análisis químicos, sabemos que el aceite utilizado en los rituales religiosos en Castro Marim, a donde llegaba envasado en ánforas, era de gran pureza; véase CARRETERo e.p.

125 Zamora et al. 2010, 207-208.

126 Véase Ruiz Mata 1999, 312, n. 17; Niveau de Villedary 2010, 657-658; Domínguez Monedero 2012, 176. Al parecer, en este solar, Blanco localizó, a 5.60 metros de profundidad, cerámica de barniz rojo y de cocina, mezclada con restos alimenticios (huesos de animales y malacofauna) y metálicos y pellas de greda verdosa, arcilla rojiza quemada y trozos de carbón (BLANCO 2002, 8-16; información gentileza de uno de los especialistas evaluadores de este escrito, a quien agradezco profundamente el dato).

127 Ruiz Mata 1999, 279-317; Córdoba - Ruiz Mata 2005; Niveau de Villedary 2008, 90.

128 Domínguez Monedero 2012, 174-175.

129 De Frutos - Muñoz Vicente 2008, 240.

130 ZAMORA et al. 2010, 235. 
una caverna con funciones cultuales y oraculares, ${ }^{131}$ datos que reflejan un culto a Astarté en su expresión marinera. ${ }^{132}$ Como se vio más arriba, el nombre alternativo de Aphrodisias, que Plinio el Viejo atribuye a Timeo y Sileno, ${ }^{133}$ refuerza la relación con Astarté y el de Iunonis insula ${ }^{134}$ también. El templo consagrado a Astarté se ha ubicado en las cercanías de la Punta del Nao, ${ }^{135}$ al pie del actual castillo de Santa Catalina, en una zona hoy sumergida. A partir de los hallazgos producidos en el área de La Caleta, el antiguo canal Bahía-Caleta y la Punta del Nao, E. Ferrer defiende una continuidad del rito en este lugar en concreto solo desde la segunda mitad del siglo VI a.C. ${ }^{136}$ En dicho caso, habría que buscar el santuario arcaico en otro lugar.

Por otra parte, Avieno cita una arx Gerontis ${ }^{137}$ que M. E. Aubet identifica con $G a-$ dir. ${ }^{138} \mathrm{El}$ nombre de este lugar no se relaciona con el personaje llamado Gerión, como supone Avieno, sino con la raíz griega $\sqrt{*}$ geront-, de la que deriva $\gamma \varepsilon ́ \rho \omega v /-\tau o \varsigma$, es decir 'viejo', de forma que arx Gerontis debe traducirse por 'fortaleza del viejo', que podría identificarse con un santuario consagrado a Baal Hammón, ${ }^{139}$ divinidad que, según Estrabón, que lo identifica con Crono, recibía culto en un santuario levantado cerca de $\Gamma \alpha ́ \delta \varepsilon \iota \rho \alpha .{ }^{140}$ Sin embargo, M. C. Marín prefiere relacionar este "viejo" -fuera cual fuese la ubicación del lugar en el Sur peninsular, no necesariamente en la isla gaditana- con uno de los dioses fenicio-púnicos vinculados a la navegación que a veces se han representado con los rasgos de Tritón. ${ }^{141}$ Se ha propuesto que el santuario dedicado a Baal Hammón pudo estar ubicado en el castillo de San Sebastián ${ }^{142}$ o en la actual calle Fray Félix, en la llamada Casa del Obispo, cerca de la Catedral. ${ }^{143} \mathrm{El}$ capitel protoeólico, datado entre los siglos VI y V a.C., ${ }^{144}$ localizado en las cercanías del castillo de San Sebastián, pudo decorar la entrada de este santuario, salvo que, como plantea M. C. Marín, el culto se iniciara en época bárcida, ${ }^{145}$ en cuyo caso habría que relacionar el capitel con otro edificio. La datación del santuario en época bárcida subrayaría la especial consagración de la isla gaditana a Astarté en los siglos anteriores, a la espera de algún dato que documente el presumible culto a Melqart.

La importancia alcanzada por los espacios cultuales dentro de las instalaciones isleñas, los elementos de arquitectura monumental, los objetos asociados a prácticas cultuales localizados en varios puntos de la actual Cádiz y la suntuosidad de algunos de ellos y la reducida población estable que el tamaño de la zona habitacional hasta

131 Avien., Ora, 314-316.

132 MARÍn 2011, 217.

133 Plin., NH., 4.120; Timae., FGH 566 F 67; Silen., FGH 175 F 7.

134 Plin., NH., 4.120.

135 Escacena 1986, 44-46; MuÑoz 1991, 332-333; De Frutos - MuÑoz 2008, 242-243.

136 FERRER 2004, 110.

137 Avien., Ora, 263, 306.

138 Aubet 2009, 273.

139 Adrados 2000, 3.

140 Str., 3.5.3.

141 Marín 2011a, 233.

142 EsCACENA 1986, 44-46.

143 De Frutos - Muñoz 2008, 254.

144 Marín - JiMÉnez 2013, 127.

145 Marín 2011a, 224-230. 
ahora conocida permite imaginar ${ }^{146}$ autorizan a pensar que la isla gaditana fue el escenario principal de las prácticas religiosas colectivas realizadas por los colonos del castillo de Doña Blanca.

Por lo que respecta al "prestigioso" templo de Melqart ubicado en Sancti Petri, cabe la posibilidad de que no estuviera inicialmente vinculado a las instalaciones fenicias documentadas en la isla gaditana. ${ }^{147}$ En este sentido, M. C. Marín sostiene que el hecho de que se trate de un santuario extraurbano, levantado a 18 kilómetros del establecimiento de la isla gaditana, situado en una zona abierta al Atlántico, puede deberse, entre otras opciones, al hecho de que realmente era un santuario independiente de dicho establecimiento, con especial advocación marinera, destacándose así su patronazgo no solo sobre Gadir sino sobre todas las colonias fenicias de la Península Ibérica. ${ }^{148}$

La cercanía a Sancti Petri de la colonia fenicia levantada en el cerro del Castillo de Chiclana ha inducido a plantear alguna relación especial entre ambos enclaves. ${ }^{149}$ La situación del hábitat humano en el cerro del Castillo de Chiclana, a la derecha del navegante, y la del santuario consagrado a Melqart en el islote de Sancti Petri, a la izquierda, parece seguir un modelo topográfico cananeo de ubicación del binomio colonia-santuario en las entradas fluviales, que se constata igualmente en el río Guadalquivir (*Spal-Sevilla ${ }^{150}$ y El Carambolo ${ }^{151}$ ) y el Guadiana (Ayamonte ${ }^{152}$ y Castro Marim ${ }^{153}$ ), pero que se aplicó también en ámbitos costeros que disponían de pasos parecidos, como el que se extendía entre la colonia fenicia de Huelva y el santuario levantado en Aljaraque ${ }^{154} \mathrm{y}$ el que se desplegaba entre la población del cerro del Castillo de Chiclana y el santuario del islote de Sancti Petri, estrecho por el que entraban en la bahía de Cádiz las naves procedentes del Este. ${ }^{155} \mathrm{Y}$ si la entrada a la bahía se producía por esta parte, la salida, en dirección a Huelva y a las costas portuguesas, podía producirse por el Norte, con la zona de los santuarios, la isla gaditana, a la izquierda del navegante y el hábitat humano, la colonia del castillo de Doña Blanca, a la derecha.

Esta hipotética especial vinculación entre el hábitat del Castillo de Chiclana y el santuario de Sancti Petri sería verosímil si se confirmara el paralelismo cronológico entre ambos lugares. Por el contrario, si se demostrara que la cronología asignada por los editores de los hallazgos a los restos chiclaneros es demasiado alta, esta situación obviamente impediría la atribución a los habitantes del lugar la fundación del santua-

146 Véase Delgado Hervás 2008, 392-393.

147 Ruiz Mata 1999, 310-311; Zamora 2006, 361.

148 Marín 2011, 214.

149 Bueno - Cerpa 2008, 204; Mederos - Ruiz Cabrero 2011, 91-92, 98.

150 Belén - Escacena 1997; Botto 2002, 43; Escacena - IzQuierdo 2008, 440-445; Escacena 2004.

151 Belén 2000 y 2001; Arruda - Celestino 2009, 30; GonzÁlez de Canales et al. 2010.

152 García Teysandier - CABACo 2010.

153 ArRUdA et al. 2009, 81-88, sostienen la existencia de una zona de culto en Castro Marim durante todas las fases de ocupación de la Edad del Hierro, en la que destacan dos edificios rectangulares con estructuras también rectangulares en su interior, que parecen corresponder a altares, con bancos corridos a lo largo de las paredes y con pisos de conchas; véase también ARRUdA - CELESTINO 2009, 34.

154 Escacena - VÁzQuez 2009, 55-56.

155 Escacena 2013, 166. 
rio, si se asume que este fue elevado en el paso del siglo IX al VIII a.C., cronología a la que, por otra parte, la Arqueología, aunque indirectamente, parece acercarse, pues algunos de los hallazgos producidos en la periferia del lugar en el que se supone se levantó el santuario (cerámica, ${ }^{156}$ punta de flecha ${ }^{157}$ y figurillas masculinas egiptizantes ${ }^{158}$ ) se pueden situar desde el siglo VIII a.C. en adelante, mientras la referencia de Mela acerca de la antigüedad del santuario ${ }^{159}$ ofrece una cronología sobre cuyos inconvenientes ya hemos tratado.

Sea como fuere, es plausible la hipótesis de la no vinculación inicial del santuario cuya ubicación la comunidad científica ha acordado ubicar en el islote de Sancti Petri con las instalaciones fenicias levantadas en el extremo septentrional de la isla gaditana. De hecho, únicamente contamos con dos referencias literarias, ya muy tardías en relación con los sucesos que pretenden narrar, que vinculan la fundación de $\Gamma \alpha ́ \delta \varepsilon 1 \rho \alpha$ con la del santuario de Heracles-Melqart. ${ }^{160}$ En caso de que esta no vinculación inicial fuera cierta y dados los especiales lazos que Estrabón y Diodoro de Sicilia señalan entre ambos lugares, cabe plantear que en algún momento determinado se produjo la apropiación en exclusiva del santuario, y la necesaria reescritura de su historia, por parte de una poderosa Gadir, firme y fundamentalmente asentada en la isla gaditana.

\section{Pesca y salazones}

Por lo que respecta a las actividades relacionadas con la pesca y el procesamiento de las capturas, como indican los hallazgos de la calle Cánovas del Castillo, la conserva de atún se documenta en la isla gaditana desde los mismos inicios del siglo VIII a.C., ${ }^{161}$ aunque los datos arqueológicos no autorizan a imaginar una distribución con repercusiones en los consumidores del Mediterráneo oriental, a pesar de que una fuente literaria en concreto induzca a la duda, pues, según el médico helenístico Euti-

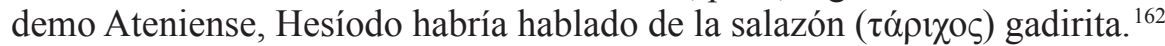

Pueden plantearse diferentes lecturas de los datos arqueológicos a la hora de establecer la importancia alcanzada por la producción de salazones y salsas saladas de pescado en la bahía de Cádiz en uno u otro siglo, pero parece que no puede ponerse en duda que la producción y exportación de ictioderivados fue en aumento a lo largo del siglo VII a.C. ${ }^{163}$ quizá solo como mercancía de segundo orden, y durante el VI, en

156 SÁEZ et al. 2005, 874-876.

157 SÁEZ et al. 2005, 874; SÁEZ 2009, 122.

158 JiMÉNEZ Ávila 2002, 284, 362, 418-419; CoRzo 2005, 93-101; SÁeZ et al. 2005.

159 Mela, 3.6.46; aunque Plinio afirmaba que se decía que el templo de Melqart en Lixus era algo anterior al del Hercules Gaditanus (Plin., NH., 19.63), referencia que, en opinión de FerRer 2010, 74, implica a Lixus en la polémica aparentemente mantenida por Gadir, Sexi y Onoba en torno a la mayor antigüedad de sus respectivas poblaciones y/o sus correspondientes santuarios.

160 Str., 3.5.5; D.S., 5.20.

161 Campanella - Niveau de Villedary 2005, 27-67; De Frutos - Muñoz 2008, 240.

162 Euthd. Ath., SHell. 455; Hes., Fr. sp. 372.

163 Escacena 2000, 126; Campanella - Niveau de Villedary 2005; Mederos - Escribano 2005; De Frutos - MuÑOZ 2008, 253. 
el que se pasó a una creciente producción excedentaria de salazones ${ }^{164}$ que en el siglo $\mathrm{V}$ se convirtió en un proceso industrial y comercial plenamente establecido que dio fama y prestigio a $\Gamma \alpha ́ \delta \varepsilon t \rho \alpha /$ Gades en todo el Mediterráneo. Ciertamente, se ha defendido la existencia, en su momento, de una destacadísima faceta como centro redistribuidor de manufacturas alóctonas y de otros productos, especialmente el estaño, ${ }^{165} \mathrm{y}$ se ha destacado la capacidad de producción (orfebrería, metalistería, vidrios, marfiles, vajillas de mesa, etc.) y de exportación de la oligarquía gadirita, ${ }^{166}$ pero no cabe duda que, a escala mediterránea, las actividades relacionadas con la transformación de productos pesqueros fueron las que dieron fama internacional a $\Gamma \alpha ́ \delta \varepsilon 1 \rho \alpha /$ Gades.

No tiene, pues, nada de extraño que fuera en la primera mitad del siglo V a.C. cuando $\Gamma \alpha ́ \delta \varepsilon ı \rho \alpha$ fuera citada por primera vez en las fuentes griegas, en un pasaje de

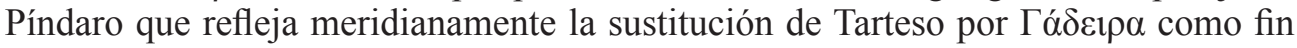
del mundo conocido, límite que se consideraba que no debía superarse ${ }^{167}$ y que fuera la salazón o mojama el primer producto relacionado con $\Gamma \alpha ́ \delta \varepsilon i \rho \alpha$ citado por dichas fuentes, en concreto, en una receta de Hipócrates para los enfermos de gota y del bazo $^{168}$ y en una referencia de Éupolis en su Maricante, ${ }^{169}$ ya en la segunda mitad del siglo $\mathrm{V}$ a.C.

\section{EI ascenso de Gadir}

Como A. J. Domínguez Monedero sostiene, no cabe duda de que a partir de un determinado momento, todavía difícil de precisar, el área en la que surgió la actual ciudad de Cádiz se convirtió en el centro principal, al menos desde el punto de vista político y religioso, de Gadir, papel que, a tenor del panorama arqueológico, no parece haber desempeñado en los momentos iniciales. ${ }^{170}$

Durante el primer cuarto del siglo VI a.C., las zonas ocupadas de la isla gaditana documentan una ocupación permanente, pero sin una estructura urbana relevante y con el predominio de los aspectos cultuales y funerarios. ${ }^{171}$ De hecho, de acuerdo con A. M. Niveau de Villedary, la mayor parte de las construcciones atestiguadas parecen corresponder a contextos religiosos, mientras que la ocupación humana se producía en torno a los centros cultuales. ${ }^{172}$

Por lo que respecta a las áreas de enterramiento, se ha defendido que los indicios de tumbas fenicias anteriores al siglo VI a.C. podrían corresponder a la presencia cananea más antigua y que no hay que descartar la existencia de otras necrópolis correspondientes a los siglos VIII-VII a.C. ubicadas al norte de las construcciones arcaicas,

\footnotetext{
164 De Frutos - Muñoz 1996, 145; SÁez 2010, 896.

165 SÁEz 2010, 896.

166 AsENSIO i Vilaró 2010, 728-729.

167 Pi., N., 4.69.

168 Hp., Int., 25, 30 Potter.

169 Eup., $199 \mathrm{Kassel} /$ Austin.

170 Domínguez Monedero 2012, 178.

171 Ruiz Mata 1999, 309.

172 Niveau de Villedary 2008, 93.
} 
pero el uso intensivo de lugares concretos para enterramientos no se inició sino a partir del segundo cuarto del siglo VI a.C., coincidiendo con la expansión del urbanismo documentado en el cruce de las calles Concepción Arenal y Botica -en el barrio de Santa María- y en la calle Paraguay -en el barrio de La Viña- y probablemente en otros lugares aún no documentados más al sur de la línea imaginaria Bahía-Caleta. ${ }^{173}$ Por debajo de ella se sitúa el sepulcro monumental hallado en la Casa del Obispo, tumba de inhumación de un personaje probablemente heroizado o divinizado, ${ }^{174}$ con una cronología del siglo VI a.C., que pertenece al inicio del periodo de transición entre el ritual de incineración y el de inhumación. ${ }^{175}$

El aumento poblacional que los datos arqueológicos documentan, teniendo en cuenta el presumible bajo nivel de población de partida, quizá no se debió especialmente al crecimiento vegetativo, sino a alguna otra causa bien distinta. Uno de los factores principales de este proceso pudo ser la llegada de fenicios desde el continente, presumiblemente huidos de unos disturbios probablemente producidos en el Bajo Guadalquivir y en la zona de Huelva, que acabarían por provocar el colapso del horizonte colonial fenicio en dichas zonas. La existencia de estos disturbios la podemos abducir a partir de algunos pocos indicios, ${ }^{176} \mathrm{el}$ primero de los cuales tiene que ver con el desarrollo y difusión de una nueva arma de guerra.

En efecto, a partir del siglo VIII a.C., seguramente en sus momentos finales, las puntas de flecha propias del Bronce Final fueron sustituidas por las denominadas puntas en anzuelo. ${ }^{177}$ La mayor parte de los hallazgos son situables en los siglos VII y VI a.C. ${ }^{178}$ y se vinculan a contextos relacionados con tensiones o conflictos en las vías de acceso a la Baja y Alta Andalucía y a las provincias de Murcia y Alicante y el valle del Segura, ${ }^{179}$ tres territorios mineros conectados a las correspondientes colonias costeras fenicias, que desempeñaron un papel crucial en el control de dichas vías de acceso al menos desde el siglo VII a.C. ${ }^{180}$ como respuesta quizá a una actitud más beligerante y una mayor capacidad de acción de los pobladores de origen peninsular.

Aunque no se está en condiciones de ofrecer una datación concreta y fiable para el uso de estas puntas de flecha en enfrentamientos bélicos, ${ }^{181}$ no es menos cierto, como sostiene F. J. Fernández Nieto, que son un testimonio de los combates que sin duda

173 TORRES 2010, 56-57.

174 Niveau de Villedary 2010, 652.

175 PeREA et al. 2004, 232.

$176 \mathrm{La}$ inferencia abductiva no se corresponde con la deductiva, en la que la conclusión se obtiene con el máximo de certeza, ni con la inductiva, en la que la conclusión probablemente es cierta si las premisas lo son, sino con el tipo de inferencia en la que la conclusión es plausible; véase PIERCE 1992, 187-189; ID. 1998, 231. Como destaca PIERCE 1998, 106, la abducción y la inducción tienen en común que ambas inferencias conducen a aceptar una hipótesis porque los hechos observados son tales que necesariamente $-\mathrm{o}$, en el caso de la abducción, probablemente- estos serían el resultado de los factores expuestos en dicha hipótesis. Plantear una hipótesis que es sugerida por determinados hechos, que es lo que se llama abducción, es una forma de inferencia en la que la hipótesis puede sustentarse, aunque puede parecer problemática; véase PIERCE 1998, 95; GABBAY - WoODS 2005.

177 García Alfonso 2000, 817.

178 García Alfonso 2000, 819.

179 Fernández Nieto 1999, 40.

180 García Alfonso 1999, 40-41.

181 García Alfonso 2000, 815. 
tuvieron que llevar a cabo los fenicios en la Península Ibérica para instalar sus colonias, explotar ciertos recursos y mantener incólumes sus asentamientos. ${ }^{182}$ Probablemente, el uso masivo de estas puntas se produjo durante el siglo VI a.C., en conexión con la etapa de inestabilidad que puede vislumbrarse para el Hierro Antiguo III, ${ }^{183}$ que repercutió muy negativamente en el mundo colonial fenicio. En este sentido, E. Ferrer relaciona la abundancia de estas puntas de flecha con un posible movimiento violento contra los fenicios e incluso contra las aristocracias ibéricas que apoyaban el sistema colonial. ${ }^{184}$

Otros indicios plantean la posibilidad de que ciertos grupos peninsulares acabaran por plantear una fuerte oposición a las manifestaciones ideológicas de los colonizadores y actuaran finalmente de forma poco pacífica. En este sentido, es asumible que los fenicios ejercieran una fuerte influencia cultural sobre los "autóctonos" en los aspectos puramente tecnológicos, carentes en gran medida de contenido ideológico o de capacidad de identificación cultural, pero en el ámbito de las ideas religiosas, de la lengua y de las costumbres funerarias, probablemente mostraron una fuerte resistencia a los influjos mediterráneos orientales, una oposición que implicó el rechazo consciente y voluntario del otro como mecanismo de defensa de la propia identidad colectiva. ${ }^{185}$ De hecho poseemos un temprano y paradigmático caso de rechazo a los fenicios en el castro Dos Ratinhos (Barragem do Alqueva, Moura), un asentamiento del Bronce Final situado junto al Guadiana. En este lugar se construyó, sobre un sitio previamente dedicado a actividades religiosas, un santuario fenicio quizá hacia 830 a.C. ${ }^{186}$ Muy presumiblemente, mediante este santuario se pretendía la transformación de las elites indígenas a través de su asociación al culto y a los procesos de explotación económica, intento que probablemente provocó episodios de rechazo y de conflictividad social culminados por el abandono del santuario y de las grandes cabañas de planta redonda asociadas, el incendio y la destrucción de la muralla y la vuelta a las costumbres tradicionales de la población del Bronce Final, en torno a 760 a.C. ${ }^{187}$ Salvo el santuario y las construcciones circulares anejas, circulares, pero fenicias, los demás materiales documentados remiten a producciones del Bronce Final local, circunstancia que se ha interpretado en el sentido de que la presencia fenicia en un lugar tan alejado de la costa y en una época tan temprana tuvo un carácter selectivo relacionado directamente con los rituales, las creencias y la estructura de poder, una presencia que obviamente fue finalmente rechazada por la población del castro. ${ }^{188}$

Otros indicios que apuntan a la existencia de actividades violentas llevadas a cabo por los habitantes de orígenes occidentales contra los fenicios e incluso contra los colaboracionistas, ${ }^{189}$ que se desarrollaron en un territorio muy concreto y no son generalizables a otras zonas peninsulares, tienen una cronología centrada en el siglo VI

\footnotetext{
182 FERnÁndeZ Nieto 1999, 41.

183 García Alfonso 2000, 815.

184 FERRER 2005, 204-205.

185 EsCACENA 2013, 140.

186 Berrocal-Rangel et al. 2012, 172, 181.

187 Berrocal-Rangel et al. 2012, 171, 181.

188 Berrocal-Rangel et al. 2012, 172.

189 Ferrer 2005, 204-205.
} 
a.C. Se trata de la ocultación de tesoros como los hallados en El Carambolo y Ebora, los niveles de incendio como los documentados en El Carambolo y Carmona y la construcción de sistemas defensivos en los centros poblacionales, como en Carmona y Lebrija, o el refuerzo de los ya existentes, como en Tejada la Vieja. ${ }^{190}$ Sabemos que, a lo largo de la primera mitad del siglo VI a.C., desapareció el barrio fenicio de Coria del Río y su santuario quedó inutilizado, ${ }^{191}$ como asimismo ocurrió con el de El Carambolo, en ambos casos a consecuencia de episodios de violencia. Por lo que concierne a *Spal, parece que la población cananea que la había fundado y habitado durante trescientos años fue expulsada de la ciudad o perdió el control de la misma. ${ }^{192}$ En cualquier caso, ni Plinio el Viejo, ni Mela, ni Silio Itálico, ni Dion Casio, ${ }^{193}$ que nombran Hispalis por diversos motivos, hacen alusión a origen fenicio alguno. Es más, Ptolomeo la sitúa en el territorio de los turdetanos. ${ }^{194}$ También dejó de usarse el cementerio de La Angorrilla, indicio de que la comunidad fenicia establecida en Ilipa desapareció del lugar. ${ }^{195}$ Castro Marim no corrió mejor suerte, pues el santuario fue abandonado repentinamente a mediados del siglo VI a.C. ${ }^{196}$ Huelva sufrió un proceso similar al seguido por el Bajo Guadalquivir y la desembocadura del Guadiana. Se poseen datos que indican la reducción de la extensión del hábitat y la pérdida de calidad de las edificaciones, ${ }^{197}$ con la construcción de viviendas más frágiles en el espacio dejado por anteriores edificaciones, en el segundo tercio del siglo VI a.C., fenómenos que, como sostiene R. Rodríguez Muñoz, pudieron estar relacionados con la marcha de los descendientes de los colonos fenicios, que abandonarían sus tierras y viviendas, mientras que los habitantes de origen peninsular volvían a levantar sus propias viviendas y/o a ocupar estructuras abandonadas por los fenicios. ${ }^{198}$ Quizá como consecuencia de este cambio demográfico, ni Plinio el Viejo, que la llama $O\{s s o\} n o b a$ Aestuaria ${ }^{199}$ ni Mela, que también la cita, si se admite la corrección de Onolappa ${ }^{200}$ en $O n o<b a>$ y Lappa, en absoluto se refieren a su pasado fenicio, mientras que Pto-

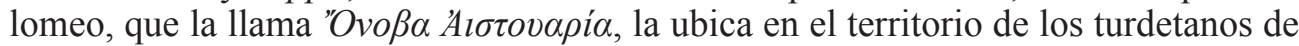
la costa atlántica. ${ }^{201}$

Estos sucesos pudieron ser consecuencias de determinadas características del proceso de la colonización fenicia al menos en el Bajo Guadalquivir y la zona de Huelva, que no tuvieron por qué haber sido muy evidentes desde el inicio de la colonización, sino que pudieron acentuarse a lo largo del tiempo, en función de la transformación de los intereses y/o necesidades de los colonizadores fenicios. En efecto, como sostiene C. G. Wagner, la presencia fenicia implicó la llegada de densos grupos de

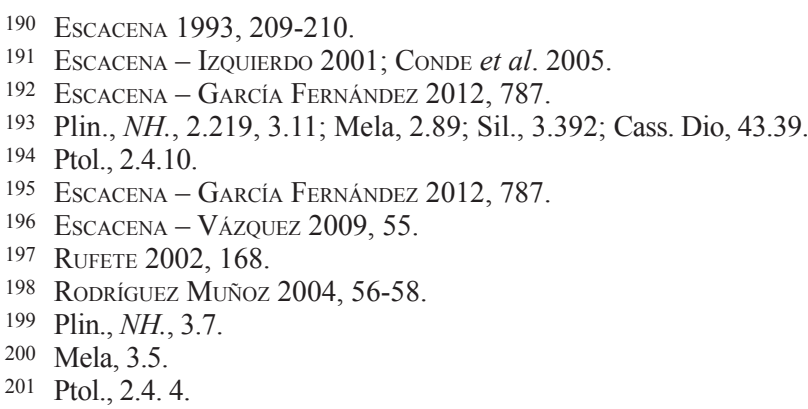


población, ${ }^{202}$ a los que se debió el predominio de una situación colonial en la que la potencia extranjera, Tiro, podía imponer sus intereses en las relaciones, ya a través del sometimiento coercitivo de los habitantes del territorio colonizado, ya a través de pactos no especialmente equitativos. Las situaciones de subordinación probablemente llegaron a predominar sobre los acuerdos voluntarios, ${ }^{203}$ condiciones de sometimiento que, en muchos casos, pudieron ser de plena esclavitud. ${ }^{204}$ C. G. Wagner subraya en este sentido que algunos elementos arqueológicos pueden estar indicando la presencia de una población local que participaba en los procesos de trabajo en los asentamientos fenicios, a los que habría sido desplazada desde sus propios territorios. ${ }^{205} \mathrm{~F}$. J. Moreno entiende además que la dinámica fenicia provocó la respuesta de determinados grupos peninsulares materializada en la simultánea aparición de una economía en parte militarista en aquellas poblaciones que poco a poco pasaron a ser intermediarias en el aprovisionamiento de esclavos a los orientales, ${ }^{206}$ cuya demanda de mercancía humana provocaría sin duda un aumento de la conflictividad entre los propios grupos peninsulares. ${ }^{207}$

Como destaca J. Alvar, la actividad coercitiva de los fenicios occidentales es sutilmente expresada por Estrabón cuando emplea el vocablo $\sigma \tau \rho \alpha \tau \varepsilon i \alpha^{208}$ para referirse a la forma concreta que tomó la expansión fenicia, esto es, mediante campañas. ${ }^{209} \mathrm{De}$ hecho, de acuerdo con F. J. Moreno, la potencia y la dinámica de la presencia cananea en la Península Ibérica permiten defender el predominio de comportamientos dirigidos a la destrucción de los recursos locales y la posterior ocupación del territorio, cuyos habitantes podían ser esclavizados o, en su defecto, expulsados. ${ }^{210} \mathrm{C}$. G. Wagner documenta este proceso en el litoral occidental malagueño, en el que, a lo largo de la primera mitad del siglo VII a.C., se produjo el abandono de poblados construidos en las inmediaciones de los enclaves fenicios, o su sustitución por núcleos de población fenicia, y la aparición de otros fortificados, dinámica en la que fortificación y desarraigo fueron algunas de las formas en las que se manifestó el miedo al fenicio. ${ }^{211}$ Las abundantes fortificaciones levantadas durante la primera Edad del Hierro estarían reflejando un alto nivel de conflictos entre las distintas comunidades que ocupaban el territorio. ${ }^{212}$

202 WAGNER 2011, 25.

203 EsCACENA 2000, 127

204 Moreno 2000, 165.

205 WAGNER 2005, 185-186.

206 Moreno 2000, 157.

207 LÓPEZ PARDO 2004, 13

208 Str., 3.2.13.

209 Alvar 1999, 399. Llama la atención en este sentido que algunos especialistas estén dispuestos a asumir la cronología derivada de los escritos de Veleyo Patérculo y no tengan en cuenta que el autor campano también afirma que Gades fue fundada por la flota tiria, gran dominadora del mar (Tyria classis, plurimum pollens mari, [...] Gadis condidit, Vell. Pat. 1.2.3), frase que no parece ponderar el comportamiento pacífico, sino el poder marítimo de los colonizadores.

210 Moreno 2008, 53-57.

211 WAGNER 2007, 127.

212 Escacena 2002, 97; López Pardo 2004, 13. 
Los fenicios consiguieron diseñar en los valles del Tinto y del Odiel, el Bajo Guadalquivir, el Bajo Guadalete y las orillas del paleoestuario del Guadalquivir un paisaje del más puro estilo colonial, en el que la escasa población de orígenes peninsulares quizá quedó integrada, básicamente, como masa social sometida al poder de los recién llegados ${ }^{213}$ y a un sistema explotador en el que la violencia era un fenómeno estructural, al que debió de recurrirse cada vez más, conforme la presencia colonial se hacía más numerosa y poderosa, ya fuera a través de las formas de explotación inherentes al sistema económico fenicio, en nada distinto del de otros pueblos mediterráneos en este sentido, ya de manera abierta a través del tráfico de esclavos destinado a satisfacer las necesidades de las colonias y la demanda oriental. ${ }^{214} \mathrm{El} \mathrm{comportamiento}$ de los fenicios en el mundo colonial por ellos diseñado no siempre mostró las mismas características en todos los casos ni en todas las ocasiones y en absoluto se debe negar el recurso a la violencia cuando los colonizadores veían conveniente su utilización. Así, una nueva lectura de la estela de Nora ha permitido a N. Pilkington sostener que la inscripción conmemora la conquista de Nuraghe Antigori por parte de los fenicios y la destrucción de la jefatura sarda que tenía esta construcción como centro. ${ }^{215}$

Puede asumirse, pues, una situación en la que la base demográfica no oriental acabó por experimentar un fuerte rechazo hacia las manifestaciones ideológicas más características de los colonizadores ${ }^{216}$ y una creciente animadversión hacia ellos. Esta situación pudo desembocar en una etapa de actividades violentas por parte de aquellos que, de una u otra forma, se sentían afectados por los aspectos más negativos del sistema colonial fenicio ${ }^{217} \mathrm{y} / \mathrm{o}$ de los que pretendían apoderarse de las riquezas acumuladas en los centros cananeos. De hecho, a partir de unas citas de Macrobio y Justino se podría reconstruir un ataque de grupos peninsulares contra el templo de Heracles $^{218}$ y los gaditani. ${ }^{219}$ En su momento, J. Alvar defendió que los sucesos narrados por Macrobio se correspondían con las actividades bélicas de un régulo contestano de mediados del siglo IV a.C. que, probablemente con ayuda de las comunidades griegas del Levante peninsular, pretendió hacerse con la ciudad de Cádiz, dentro de una dinámica de situaciones hostiles locales en el Mediterráneo occidental a la que las dos grandes potencias del momento, Roma y Cartago, quisieron poner coto mediante un acuerdo que se plasmaría en el denominado segundo tratado romano-cartaginés (de 348 a.C.). ${ }^{220}$ De todas formas, el rey Therón citado por Macrobio quizá no era realmente (un) rey de la Hispania Citerior, aun considerando la información de Macrobio (Theron, rex Hispaniae Citerioris) como una actualización errónea o un anacronismo, sino, como traduce G. Chic, "rey de la Hispania más cercana" a Gadir, ${ }^{221}$ versión que permite concederle al evento un carácter más local. En otro lugar, J. Alvar ha

\footnotetext{
213 ESCACENA - IZQUIERDO 2008, 433.

214 ORdóÑEZ 2012, 20.

215 Pilkington 2012, 49.

216 ESCACENA 2013, 149.

217 ORDÓÑEZ 2011, 19.

218 Macr., Sat., 1.20.12.

219 Iustin., 44.5.1-3.

220 Alvar 1986, 173-175.

221 Снiс 1984, 59.
} 
defendido que, a partir de dos citas de Justino y Vitrubio, ${ }^{222}$ se podría reconstruir un ataque de grupos peninsulares contra Gadir, su conquista después de algún que otro intento y la posterior reconquista por parte de las armas cartaginesas. ${ }^{223}$ Sin embargo, M. Álvarez defiende que la narración del ataque a Gades por parte de los cartagineses probablemente responde a enfrentamientos reales entre Gadir y Cartago producidos en otros momentos y circunstancias y no a una liberación de la ciudad de manos enemigas. ${ }^{224}$

A pesar de que es difícil ubicar estos eventos y asumir que realmente se produjeron en los mismos términos en los que dichas fuentes los narran, es evidente que las citas de Macrobio y Justino transmiten una idea general de violencia contra los fenicios, quizá simbolizados por Gadir/Gades porque esta era la única población del suroeste peninsular que se vinculaba inequívocamente a los fenicios cuando se fijaron por escrito estas noticias.

¿Qué respuesta podía esperarse de Tiro en aquellas circunstancias, en el caso de que efectivamente se hubiesen dado? Tras la caída de la ciudad en manos de Nabucodonosor, en 573 a.C., la monarquía se mantuvo en la metrópolis fenicia como forma de gobierno, pero parece evidente que Tiro había perdido la poca capacidad que tuviera para intervenir en sus posesiones occidentales, si aún seguían siéndolo. Esta situación debió de agravarse a lo largo de la segunda mitad del siglo VI a.C. Por aquellos momentos, con toda probabilidad la vieja metrópolis cananea no tenía capacidad alguna para gobernar sus colonias en Occidente. A finales de dicho siglo, Tiro quedó incluida en el Imperio persa y la flota fenicia se convirtió en la base del poder marítimo aqueménida en el Mediterráneo. La situación se hizo irreversible.

Si estos sucesos violentos realmente se produjeron, como podría inferirse de los indicios reseñados, no sería extraño que muchos descendientes directos de los fenicios y otros grupos de orientales salieran del Bajo Guadalquivir y de la zona de Huelva a lo largo del siglo VI a.C. Este hipotético abandono del territorio indicado podría explicar la desaparición de todos aquellos elementos que reflejaban usos, inspiración o gustos orientales (marfiles, escritura, imágenes de dioses, orfebrería, santuarios, toréutica, etc.), del abandono de multitud de enclaves rurales de pequeño tamaño y del cese del ritual funerario de enterramiento en tumbas, ${ }^{225}$ mientras en el Guadalquivir Medio, la Alta Andalucía y el sureste peninsular, siguieron vigentes elementos orientales que habían desaparecido ya del Bajo Guadalquivir y la zona de Huelva. ${ }^{226}$ De acuerdo con S. Celestino, la periferia de este territorio debió de asumir en el siglo VI a.C. todo el control de sus propios excedentes agropecuarios y reorientar sus intercambios hacia el Sureste, lo que debió de repercutir positivamente en la potenciación de sus sistemas de control político, una situación que alcanzaría su máxima expresión a finales del VI y, sobre todo, a lo largo del V a.C. ${ }^{227}$

222 Iustin. 44.5.1; Vitr. 10.13.1; Ath.Mech. 4.9.3.

223 AlVAr 1993, 196-197.

224 Álvarezz 2006, 131-135.

225 EsCACENA 2011, 178.

226 EsCACENA 2013, 176

227 Celestino 2000, 132-134. 
Los pobladores de origen oriental que optaran por abandonar el territorio, si se dieron las circunstancias planteadas en esta hipótesis de trabajo, tendrían como opción más inmediata el refugio en algunas colonias de la costa malagueña y gaditana. ${ }^{228} \mathrm{La}$ isla gaditana presentaba excelentes ventajas desde el punto de vista de la defensa por su insularidad y no sería extraño que se convirtiera en refugio de una buena cantidad de exiliados. Probablemente, Gadir, la insular, quizá llamada así desde entonces, se convirtió en una de las ciudades fenicias más importantes del sur peninsular; si no la más.

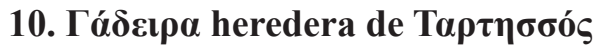

Desde entonces, Gadir construyó, o al menos lo intentó, un discurso ideológico con el objetivo de justificar y legitimar el papel hegemónico que pretendía alcanzar sobre el resto de las comunidades fenicias occidentales, a través de una propaganda de la que formaría parte la leyenda fundacional recogida por Estrabón, ${ }^{229}$ apelando al común origen tirio de todas ellas y a la antigüedad de sí misma y de su santuario o, mejor dicho, del santuario de Melqart levantado en el islote de Sancti Petri del que se habría apropiado. Quizá los gadiritas no alcanzaron todos sus objetivos hegemónicos, ${ }^{230}$ pero Gadir, la gran suministradora de ictioderivados, sí alcanzó una creciente fama entre los griegos.

En efecto, culminada la crisis del horizonte colonial del Bajo Guadalquivir y la

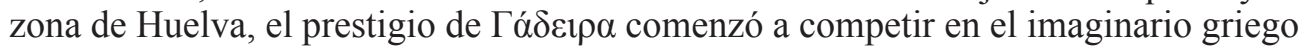
con el de Tarteso, el más famoso referente mítico-geográfico del Extremo Occidente mediterráneo junto con las Columnas de Heracles. Como sostenía en su momento R. Olmos, en el siglo V a.C., Гá $\delta \varepsilon ı \alpha \alpha$, en etapa ascendente, fue oscureciendo a Tarteso, de forma que el prestigioso nombre de Tarteso y los mitos a él vinculados se fueron trasladando de Oeste a Este, ${ }^{231}$ relacionándose la isla Eritea de una forma u

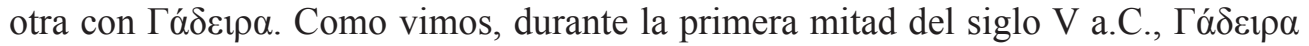
es citada por primera vez en las fuentes griegas, ocupando el lugar de Tarteso y de las Columnas de Heracles como fin del mundo conocido. Por otra parte, a pesar de la interrupción de los contactos directos entre griegos y el sur de la Península Ibérica, las fuentes literarias helenas nombran por primera vez a los habitantes de Tarteso, los tartesios, ${ }^{232}$ y citan animales que lo habitaban o que vivían en sus costas. ${ }^{233}$ Como se vio más arriba, durante la segunda mitad de dicho siglo, comenzaron a ser mencionadas las salazones gaditanas.

228 ORDÓÑEZ 2011, 19; EsCACENA 2013, 159.

229 Álvarez - Ferrer 2009, 191.

230 FERrER 2010, 71-82, opina que no puede sostenerse con argumentos sólidos la existencia de un liderazgo político-religioso de Gadir sobre el resto de las comunidades púnicas de Iberia durante los siglos VI-II a.C.

231 Olmos 1986, 587 y 597.

232 Herodor., FGH 31 F 2 a.

233 Heródoto documenta la existencia de mustélidos en Tarteso (Hdt., 4.192; véase Sud., Lex., $\gamma$ 29). Aristófanes, por su parte, cita la morena tartésica (Ar., Ra., 474-475; véase Sud., Lex., $\tau$ 136-137, 1124). 


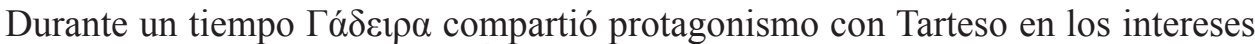
literarios helenos. Si Aristóteles, Éforo de Cumas y Teopompo se referían en sus escritos a Tarteso y los tartesios, ${ }^{234}$ Antífanes citaba la mojama o salazón de $\Gamma \alpha ́ \delta \varepsilon i \rho \alpha,{ }^{235}$

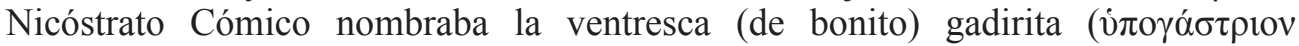
$\Gamma a \delta \varepsilon ı$ เı́óv), ${ }^{236}$ Platón daba a uno de los reyes de la isla de la Atlántida el nombre de

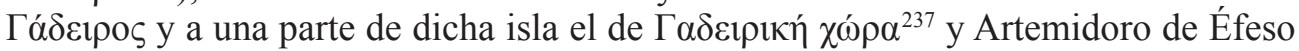
aludía a comerciantes gadiritas. ${ }^{238}$ Pero a lo largo del siglo IV a.C., se produjo una fractura en las relaciones literarias entre $\Gamma \alpha ́ \delta \varepsilon i p \alpha$ y la erudición griega, como consecuencia de la pérdida de contacto de los helenos con las fuentes de información más directamente ligadas a Occidente, ${ }^{239}$ de manera que se redujeron acusadamente las posibilidades de que la literatura griega terminara por identificar $\Gamma \alpha ́ \delta \varepsilon \imath \rho \alpha$ con Tarteso. De hecho, durante el siglo I a.C., se impuso entre los eruditos griegos la idea de

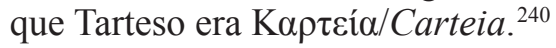

Durante el siglo I a.C., el historiador latino de origen galo Pompeyo Trogo, cuya obra conocemos por el resumen que Justino realizó en el siglo III d.C., recogía un supuesto mito ibérico, el de Gárgoris y Habis, ${ }^{241}$ que en realidad formaba parte de la mitificación reivindicativa de una presencia eubea en el Extremo Occidente muy anterior a la de los fenicios, en la que los eubeos, en concreto los calcídicos, forjaron un hermanamiento con los tartesios a través de unos ancestros comunes, los curetes, considerados los primeros calcídicos y los antepasados de los tartesios. ${ }^{242}$ La ubicación de estos míticos curetes en el entorno de la bahía de Cádiz pudo quedar reflejada en el nombre de curense que Plinio el Viejo atribuye a una zona costera del sur de Iberia, ${ }^{243}$ probablemente la que se extiende frente a Cádiz, desde Rota hasta Puerto Real o, tal vez, hasta el castillo de Sancti Petri, ${ }^{244}$ es decir, en el entorno inmediato de Gades, lugar en el que una corriente erudita latina ubicó Tartessus.

En su momento, J. Alvar propuso que la inexistencia de estructuras urbanas en el Bronce Final de la Baja Andalucía provocó que Gadir, al ser la primera y única ciudad, por aquellos momentos, de la región, pronto pasaría a ser identificada como la ciudad por antonomasia, el punto de referencia urbano dentro del ámbito indígena, de manera que el nombre poco significativo de la nueva ciudad, Gadir, que no permitía una clara diferenciación de otras fundaciones, fue identificada, tanto en Oriente como en Occidente, como la ciudad de Tarteso, circunstancia que permite entender la identificación posterior de Tarteso-ciudad con Gades. ${ }^{245}$ Pero esta hipótesis no explica

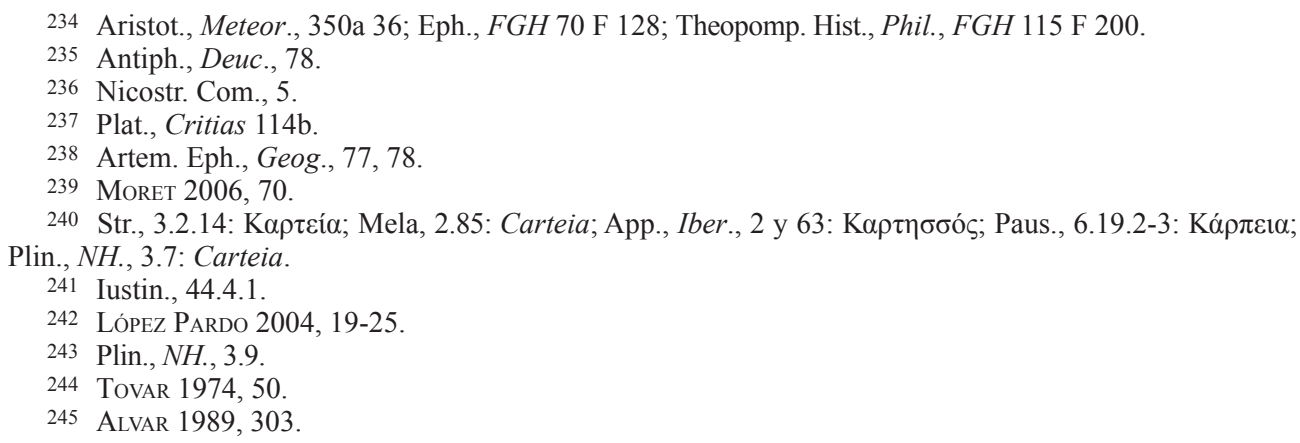


satisfactoriamente por qué esta identificación solo se manifestó en las fuentes latinas. Por su parte, M. Álvarez defiende que las fuentes literarias antiguas aludieron con el nombre de Tarteso principalmente a las comunidades fenicias implantadas en el suroeste de la Península Ibérica y al paisaje colonial por ellas constituido, sosteniendo que la identificación de Tarteso y Gadir presente en las fuentes latinas no respondería a la vinculación, a posteriori, de dos entidades históricas diferentes, sino a que, desde fechas tempranas, Tarteso pudo haber sido un topónimo vinculado al mundo fenicio colonial de la Península Ibérica y que es probable que los fenicios estuvieran siendo citados implícitamente a través de su colonia más visitada por los griegos: Gadir. ${ }^{246}$ Pero entiendo que la Arqueología indica, según los hallazgos hasta ahora producidos, que los griegos, siempre por lo que se refiere al sur peninsular sensu stricto, conocieron esta realidad colonial fenicia fundamentalmente a través de Huelva y que los pri-

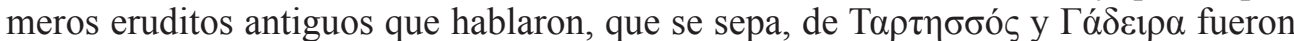
griegos, y fueron eruditos griegos quienes posteriormente acabaron por identificar Tarteso con Carteia, mientras que la erudición latina lo hizo con Gadir-Gades.

En efecto, si en la literatura griega se produjo la sustitución de Tarteso por $\Gamma \alpha ́ \delta \varepsilon \imath \rho \alpha$ como límite occidental del mundo conocido, ${ }^{247}$ en la literatura latina se produjo la identificación de Tarteso con Gades, que señalaba el final del mundo romano por el Occidente, primero en el plano ideológico y poco después en el real, pues en ella tendría su final la vía Augusta, que se iniciaba en Roma. ${ }^{248} \mathrm{Y}$ si Gades se identificó con Tarteso, lo tartesio se identificó con lo gaditano. Así, Cicerón llamaba tartesio al gaditano L. Cornelio Balbo ${ }^{249}$ y hacía gaditano a Argantonio, ${ }^{250}$ Salustio indicaba que los fenicios habían sustituido el nombre de Tarteso por el de Gadir, ${ }^{251}$ y el gaditano Columela situaba Gades en la orilla de Tarteso. ${ }^{252}$ Valerio Máximo y Plinio el Viejo, como Cicerón, convertían a Argantonio en gaditano. ${ }^{253}$. Por su parte, Plinio el Viejo subrayaba que los romanos llamaban Tarteso a la isla de Gades y que Gadir era el nombre utilizado por los púnicos. ${ }^{254}$ Por su parte, Silio Itálico también identifica Gades con Tarteso. ${ }^{255}$ En el caso de Avieno, la identificación de Gades con Tarteso ${ }^{256}$ queda fuera de toda duda. Parece que Gades asumió interesada y gustosamente las connotaciones históricas que implicaba su identificación con Tarteso. ${ }^{257}$

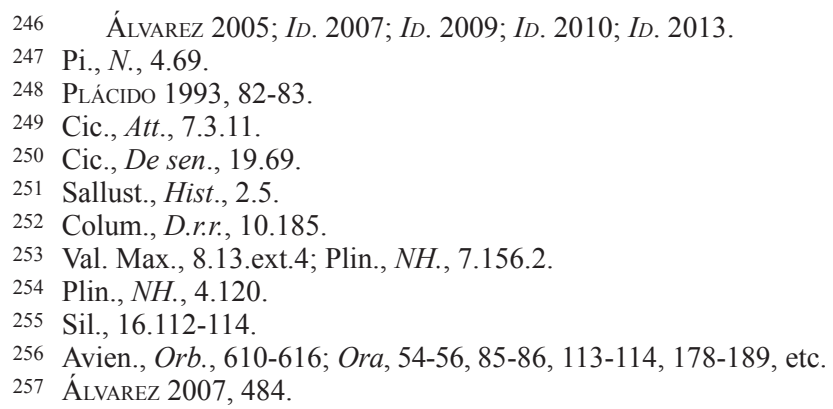




\section{Conclusiones}

La paleogeografía del territorio en el que se asentaba Gades indica que, desde antes del siglo IX a.C., existía una única isla de buen tamaño, la isla gaditana, y un islote, el de Sancti Petri, este último en condiciones similares a las actuales. El brazo de mar conocido como canal Bahía-Caleta, que en etapas anteriores actuó de separación entre una isla pequeña y otra mayor, estaba ya cegado por la zona central, aunque dejaba una ensenada que miraba hacia Poniente y otra hacia Levante.

Es un lugar común llamar Gadir a las construcciones levantadas por los fenicios en la zona más septentrional de la isla gaditana porque hay un par de fuentes de época romana que utilizan ese término para referirse a una entidad poblacional identificable con la Gades romana. El topónimo Gadir parece ser una realización de la base trilítera semítica /g-d-r/ ('pared, muro, muralla, montón de piedras', etc.). El problema es que no se han hallado testimonios de sistema defensivo antiguo alguno en la actual península gaditana y parece que el nombre que se atribuye a las estructuras levantadas en la isla no se corresponde sensu stricto con lo que la Arqueología puede atestiguar, frente a las magníficas murallas documentadas en el castillo de Doña Blanca y en el cerro del Castillo de Chiclana, por ejemplo. Cuando las fuentes griegas comienzan a hablar, en la primera mitad del siglo $\mathrm{V}$ a.C., de una población que podemos relacionar directamente con la Gades romana utilizan el término $\Gamma \alpha ́ \delta \varepsilon \imath \rho \alpha$, mientras, si damos crédito a Plinio el Viejo y Avieno, los púnicos la llamaban Gadir. Pero de aquí no se deduce necesariamente que este fuera el nombre del establecimiento fenicio levantado tiempo atrás en el norte del brazo occidental de la isla gaditana. Otro enclave cercano a la isla gaditana pudo ser quizá la Gadir arcaica. El lugar pudo ser el castillo de Doña Blanca. Pero, esta no es la única respuesta. Es posible que el crecimiento poblacional de las instalaciones insulares, en detrimento del enclave que hasta entonces hubiera portado el nombre de Gadir, implicara el traslado del topónimo al lugar que adquirió el mayor peso específico dentro de las instalaciones fenicias distribuidas por la bahía de Cádiz, esto es, la ciudad finalmente conformada en la isla gaditana.

Las descripciones antiguas del lugar en el que presumiblemente se asentaron $\mathrm{Ga}$ des y el santuario de Melqart supuestamente vinculado a la población no solo no se adecúan siempre a la paleogeografía del lugar, sino que mantienen marcadas diferencias entre sí, de tal manera que inducen a pensar que las referencias literarias son creaciones con bases geográficas poco reales, pero suficientes para construir un escenario literario creíble.

A pesar de que una fuente literaria asegura que Gadir fue la colonia tiria más antigua más allá de las Columnas de Heracles, la Arqueología demuestra, por ahora, que el primer establecimiento fundado por los fenicios más allá del estrecho de Gibraltar se levantó en terrenos del actual casco urbano de Huelva, probablemente en el segundo cuarto del siglo IX a.C. La narración que defiende la primacía cronológica de Gadir sobre Sexi y Onoba, en esencia un mensaje especialmente dirigido por la oligarquía gadirita al resto de los fenicios occidentales, era la típica leyenda que reafirmaba la idea de los habitantes de Gadir de hallarse en el mejor de los lugares posibles, que otorgaba a la fundación de la ciudad el carácter de una fundación per- 
fecta y que los convertía en los únicos herederos del dominio que, según su opinión, les había concedido Melqart.

Frente a las fuentes literarias que elevan la fundación de Gadir incluso a los inicios del siglo XII a.C., una datación poco asumible, vista la muy problemática naturaleza desde el punto de vista histórico de los sucesos supuestamente ocurridos a la vez que la fundación de Gadir, la Arqueología permite afirmar que la presencia tiria en la bahía de Cádiz pudo iniciarse en el paso del siglo IX al VIII a.C.

Las estructuras levantadas en la parte norte del brazo occidental de la isla gaditana durante los siglos IX-VII a.C. no parecen corresponder a una gran ciudad vertebradora de la colonización fenicia del Extremo Occidente. De hecho, no puede demostrarse fehacientemente la existencia de un asentamiento urbano permanente de gran envergadura durante dichos siglos. La reducida población estable que se deduce del tamaño de la zona habitacional hasta ahora documentada arqueológicamente y la suntuosidad de los objetos cultuales hallados inducen a pensar que la isla probablemente fue el escenario de prácticas religiosas desarrolladas por los habitantes de la colonia del castillo de Doña Blanca, un asentamiento amurallado de gran tamaño desde sus inicios, aparecido también en el paso del siglo IX al VIII a.C. Por su parte, cabe la posibilidad de que el "prestigioso" templo de Melqart presumiblemente levantado en el islote de Sancti Petri no estuviera inicialmente vinculado de forma exclusiva a las edificaciones fenicias documentadas en la isla gaditana, aunque con posterioridad se produjo, si la vinculación efectivamente no se produjo desde el principio, la apropiación del santuario por parte de una poderosa Gadir, firme y fundamentalmente asentada en la isla gaditana.

La isla gaditana fue también, desde bien pronto, centro de actividades pesqueras y de procesado de las capturas, que se convirtieron, en el siglo $\mathrm{V}$ a.C., en un proceso industrial y comercial plenamente establecido que dio fama y prestigio a $\Gamma \alpha ́ \delta \varepsilon t \rho \alpha /$ Gades en todo el Mediterráneo.

Durante el primer cuarto del siglo VI a.C., la isla gaditana documenta una ocupación permanente, pero sin una estructura urbana relevante, correspondiendo la mayor parte de las construcciones documentadas a contextos religiosos, en cuyo entorno se producía la ocupación humana. Pero, según avanzó dicho siglo, se produjo un crecimiento demográfico, arqueológicamente documentado por el desarrollo de las necrópolis, que pudo ser consecuencia directa especialmente de la llegada de población establecida en el Bajo Guadalquivir y zona de Huelva, presumiblemente obligada a abandonar dichos territorios, según puede inferirse de algunos indicios, por los disturbios producidos en contra de los colonizadores, que acabaron por provocar el colapso del horizonte colonial fenicio en dichas zonas. Esta situación puede hallar una explicación en las características que el proceso de la colonización fenicia acabó por adquirir al menos en dichos territorios, que implicó una serie de fricciones con la población peninsular, sometida a un sistema explotador en el que la coerción y la violencia fueron fenómenos, quizá no muy evidentes en la etapa inicial de la colonización, que se acentuaron con el paso del tiempo al menos en esta zona, probablemente en función de la transformación de los intereses y/o las necesidades de los colonizadores. 
Gadir, quizá así llamada desde entonces, acabó por convertirse en la más importante ciudad fenicia del sur peninsular. Desde su nueva posición, Gadir intentó construir un discurso ideológico con el objetivo de justificar y legitimar el papel hegemónico que intentaba alcanzar sobre el resto de las ya pocas comunidades fenicias occidentales, apelando al común origen tirio de todas ellas y a la primacía cronológica de sí misma y del santuario de Melqart levantado en el islote de Sancti Petri, del que se habría apropiado en su momento.

Culminada la crisis del horizonte colonial fenicio en el Bajo Guadalquivir y en la

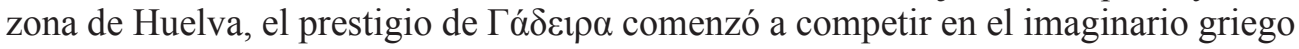
con el de Tarteso, cuyo prestigioso nombre y los mitos a él vinculados se trasladaron hacia el Este y se relacionaron de una forma u otra con $\Gamma \alpha ́ \delta \varepsilon t \rho \alpha$. Durante un tiempo, $\Gamma \alpha ́ \delta \varepsilon i p \alpha$ compartió protagonismo con Tarteso en los intereses literarios helenos. Pero a lo largo del siglo IV a.C., se produjo una fractura en las relaciones literarias entre $\Gamma \alpha ́ \delta \varepsilon ı \rho \alpha$ y la erudición griega, de manera que se redujeron acusadamente las posi-

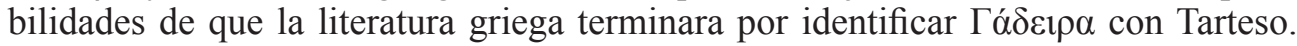
De hecho, durante el siglo I a.C., se impuso entre los eruditos griegos la idea de que

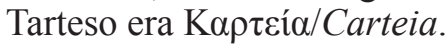

Si en la literatura griega se produjo la sustitución de Tarteso por $\Gamma \alpha ́ \delta \varepsilon ı \rho \alpha ~ c o m o$ límite occidental del mundo conocido, en la literatura latina se produjo la identificación de Tarteso con Gades, que señalaba el final del mundo romano por el Occidente, primero en el plano ideológico y poco después en el real, pues en ella tendría su final la vía Augusta, que se iniciaba en Roma.

\section{BIBLIOGRAFÍA}

Adrados, F. R. (2000): “Topónimos griegos en Iberia y Tartessos”, Emerita 68/1, 1-18.

Almagro-Gorbea, M. - Lorrio, A. J. - Mederos, A. - Torres, M. (2011-2012): "El mito de Telepinu y el altar primordial en forma de piel de toro", CuPAUAM 37-38, 241-262.

Almagro-Gorbea, M. - Torres, M. (2007): "Las fortificaciones tartésicas en el Suroeste peninsular", [en] Berrocal-Rangel - Moret (eds.), 2007, 35-56.

AlvAR, J.

(1986): “Theron, rex Hispaniae Citerioris (Macr., Sat. I, 20, 12)”, Gerión 4, 161-175.

(1989): "Tartessos-ciudad = Cádiz. Apuntes para una posible identificación", [en] Homenaje a Santiago Montero Díaz (=Anejos de Gerión 2), Madrid, 295-306.

(1993): "El ocaso de Tarteso", [en] Alvar - Blázquez (eds.), 1993, 187-200.

(1999): "Manifestaciones religiosas", [en] J. Ma Blázquez - J. Alvar - C. G. Wagner, Fenicios y cartagineses en el Mediterráneo, Madrid, 388-403.

Alvar, J. - Blázquez, J. Ma (eds.), (1993): Los enigmas de Tarteso, Madrid.

ÁlVAREZ, M.

(2005): Tarteso. La construcción de un mito en la historiografía española, Málaga.

(2006): "El origen del ariete: Cartago versus Gadir a fines del s. III a.C.”, [en] J. Martínez

Pinna (coord.), Initia rerum. Sobre el concepto del origen en el mundo antiguo (=Thema 49), Málaga, 125-140. 
(2007): “Arganthonius Gaditanus. La identificación de Gadir y Tarteso en la tradición antigua", Klio 89/2, 477-492.

(2009): "Identidad y etnia en Tartesos", Arqueología Espacial 27, 79-111.

(2010): “Tartesios: un etnónimo de la Iberia púnica”, Mainake 32/1, 395-406.

(2013): "Notas sobre Tarteso y los fenicios peninsulares en las fuentes literarias grecolatinas: el caso de Gadir", [en] Arruda (ed.), 2014, vol. 1, 115-119.

Álvarez, M. (ED.), (2011): Fenicios en Tartesos: nuevas perspectivas (=BAR International Series 2245), Oxford.

Álvarez, M. - Ferrer, E. (2009): "Identidad e identidades entre los fenicios de la Península Ibérica en el periodo colonial”, [en] F. Wulff - M. Álvarez (eds.), Identidades, culturas y territorios en la Andalucía prerromana (=Serie Historia y Geografía 153), Málaga, 165204.

Anderson, Fr. I. - Forbes, A. D. (1992): The vocabulary of the Old Testament, Roma.

Arteaga, O. - Kölling, A. - Kölling, M. - Roos, A. M. - Schulz, H. - Schulz, H. D. (2001): "El puerto de Gadir. Investigación geoarqueológica en el casco antiguo de Cádiz", RAMPAS 4, 345-415.

Arteaga, O. - Roos, A. M. (2002): “El puerto fenicio-púnico de Gadir. Una nueva visión desde la geoarqueología urbana de Cádiz”, Spal 11, 21-39 (http://dx.doi.org/10.12795/ spal.2002.i11.02).

Arteaga, O. - Schulz, H. D. - Roos, A. M. (2008): "Geoarqueología dialéctica en la bahía de Cádiz”, RAMPAS 10, 21-116.

Arruda, A. M. (ED.), (2013): Fenícios e Púnicos, por terra e mar. Actas do VI Congresso Internacional de Estudos Fenícios e Púnicos (=Estudos \& Memórias 5), Lisboa.

Arruda, A. M. - Carretero, P. A. - Teixeira de Freitas, V. - Sousa, E. - Bargao, P. - LouRenço, P. - Oliveira, C. F. (2009): "Castro Marim: un santuario en la desembocadura del Guadiana", [en] Mateos et alii (eds.), 2009, 79-88.

Arruda, A. M. - Celestino, S. (2009): “Arquitectura religiosa en Tartessos”, [en] Mateos et alii (eds.), 2009, 29-77.

Asensio i Vilaró, D. (2010): “Evidencias arqueológicas de la incidencia púnica en el mundo ibérico septentrional (siglos VI-III a.C.). Estado de la cuestión y nuevos enfoques", Mainake 32/2, 705-734.

Aubet, M. E.

(2006): “El sistema colonial fenicio y sus pautas de organización”, Mainake 28, 35-47.

(2009): Tiro y las colonias fenicias de Occidente, Barcelona.

BELÉN, M.

(2000): "Santuarios fenicios y comercio en Tartessos", [en] Fernández Uriel - Wagner López Pardo (coords.), 2000, 293-312.

(2001): “Arquitectura religiosa orientalizante en el Bajo Guadalquivir", [en] Ruiz Mata Celestino (eds.), 2001, 1-16.

BelÉn, M. - Escacena, J. L. (1997): “Testimonios religiosos de la presencia fenicia en Andalucía Occidental”, Spal 6, 103-131 (http://dx.doi.org/10.12795/spal.1997.i6.07).

Benítez, E. (2009): "Proverbios, tópicos y mitología clásica: relación con el refranero castellano (II)", Paremia 18, 87-98. 
Berrocal-Rangel, L. - Moret, P. (eds.), (2007): Paisajes fortificados de la edad del Hierro. Las murallas protohistóricas de la Meseta y de la vertiente atlántica en el contexto europeo (=Publicaciones del Gabinete de Antigüedades de la Real Academia de la Historia, Bibliotheca Archaeologica Hispana 28), Madrid.

Berrocal-Rangel, L. - Silva, A. C. S. - Prados, F. (2012): "El castro Dos Ratinhos. Un ejemplo de orientalización entre las jefaturas del Bronce Final del Suroeste", [en] J. Jiménez Ávila (ed.), Sidereum Ana II. El río Guadiana en el Bronce Final (=Anejos de AEspA 62), Mérida, 167-183.

Blanco, F. J. (2002): Comentario de los resultados arqueológicos obtenidos del sondeo realizado en la c/ Marqués del Real Tesoro, 13 (Cádiz), Informe depositado en la Delegación de Cultura de la Junta de Andalucía en Cádiz, Cádiz.

Bотто, M. (2002): "Raporti fra fenici e indigeni nella Penisola Iberica (VIII-VI sec. a.C.)", [en] G. Urso (ed.), Hispania Terris Omnibus Felicior. Premesse ed esiti di un processo di integrazione (Atti del Convegno internazionale, Cividale del Friuli, 27-29 settembre 2001), Pisa, 9-62.

Bueno. P. - Cerpa, J. A. (2008): “Un nuevo enclave fenicio descubierto en la bahía de Cádiz: el Cerro del Castillo, Chiclana", Spal 17, 169-206 (http://dx.doi.org/10.12795/spal.2008. i17.08).

Bueno. P. - García Menárguez, A. - Prados, F. (2013): “Murallas fenicias de Occidente. Una valoración conjunta de las defensas del Cerro del Castillo (Chiclana, Cádiz) y del Cabezo Pequeño del Estaño (Guardamar, Alicante)", Herakleion 6, 27-75.

Calderón, J. (2001): Avieno, Fenómenos. Descripción del orbe terrestre. Costas marinas, Madrid.

Campanella, L. - Niveau de Villedary, A. M. (2005): "Il consumo di pescato nel Mediterraneo fenicio e punico. Fonti letterarie, contesti archeologici, vasellame ceramico, Greci, fenici, romani: interazioni culturali nel Mediterraneo Antico", Daidalos 7, 27-67.

Campos, J. M. - Alvar, J. (eds.), (2013): Tarteso. El emporio del metal, Córdoba.

CARAYON, N. (2008): Les ports pheniciens et puniques. Geomorphologie et infrastructures, These de Doctorat, Université Strasbourg II-Marc Bloch.

Carretero, P.A. (e.p.): "El uso del aceite de oliva en los rituales religiosos de Castro Marim durante el período púnico-turdetano", [en] III Encontro de Arqueologia do Algarve (Silves, 2005), [https://www.academia.edu/209031; acceso el 08/11/2013].

Celestino Pérez, S. (2000): “Intercambio y estructuras comerciales en el interior de la Península Ibérica”, [en] Fernández Uriel - Wagner - López Pardo (coords.), 2000, 125-138.

Celestino Pérez, S. - Jiménez Ávila, J. (eds.), (2005): El periodo Orientalizante. Actas del III Simposio Internacional de Arqueología de Mérida: Protohistoria del Mediterráneo Occidental. I (=Anejos de AEspA 35), Mérida, 2 vols.

Chic, G. (1984): Cádiz. Historia Antigua, Sevilla.

Cohen, D. - Bron, Fr. - Lonnet, A. (1994): Dictionnaire des racines sémitiques: ou attestées dans les langues sémitiques. Fasc. 2: 'TN/-GLGL, Paris-Louvain.

Conde, M. - Izquierdo, R. - Escacena, J. L. (2005): "Dos escarabeos del santuario fenicio de Caura en su contexto histórico y arqueológico", Spal 14, 75-89 (http://dx.doi.org/10.12795/ spal.2005.i14.03). 
Córdoba, I. - Ruiz Mata, D. (2005): “El asentamiento fenicio arcaico de la calle Cánovas del Castillo (Cádiz). Un análisis preliminar”, [en] Celestino Pérez - Jiménez Ávila (eds.), 2005, vol. 2, 1269-1322.

Corzo, R. (2005): "Sobre las primeras imágenes y la personalidad originaria de Hercules Gaditanus", Spal 14, 91-122 (http://dx.doi.org/10.12795/spal.2005.i14.04).

Cruz Andreotti, G. (1994): "La visión de Gades en Estrabón. Elaboración de un paradigma geográfico", DHA 20/1, 57-85.

Dagmar, U. (1996): “Creencias y mitos en el uso del número en tres culturas europeas”, Rev. Murciana Antrop. 3, 61-70.

De Frutos, G. - MuÑoz, A.

(1996): "La industria pesquera y conservera púnico-gaditana: balance de la investigación. Nuevas perspectivas", Spal 5, 133-165 (http://dx.doi.org/10.12795/spal.1996.i5.07). (2004): "La implantación colonial fenicia arcaica en el archipiélago de las Gadeira: una propuesta para el debate", Huelva en su Historia (2 época) 11, 83-106.

(2008): "La incidencia antrópica del poblamiento fenicio-púnico desde Cádiz a Sancti Petri”, RAMPAS 10, 237-266.

Delgado Hervás, A. (2008): "Fenicios en Iberia”, [en] F. Gracia Alonso (coord.), De Iberia a Hispania, Madrid, 347-474.

Domínguez Monedero, A. J. (2012): “Gadir”, [en] C. Fornis Vaquero (coord.), Mito y arqueología en el nacimiento de las ciudades legendarias de la Antigüedad, Sevilla, 153-197.

$E L_{1}=$ M. Th. Houtsma - T. W. Arnold - R. Basset - R. Hartmann, (eds.), Encyclopaedia of Islam, First Edition, [URL: http://referenceworks.brillonline.com/browse/encyclopaediaof-islam-1/alpha/a?s.start=520; acceso el 21/05/2014].

$E L_{2}=$ P. Bearman - Th. Bianquis - C. E. Bosworth - E. Van Donzel - W. P. Heinrichs (eds.), Encyclopaedia of Islam, Second Edition [URL: http://referenceworks.brillonline.com/ browse/encyclopaedia-of-islam-2/alpha/a?s.start=660]; Encyclopaedia of Islam, Second Edition. Glossary and Index of Terms [URL: http://referenceworks.brillonline.com/browse/encyclopaedia-of-islam-2-Glossary-and-Index-of-Terms /alpha/a?s.start=80; acceso el 21/05/2014].

$E L_{3}=$ K. Fleet - G. Krämer - D. Matringe - J. Nawas - E. Rowson (eds.), Encyclopaedia of Islam, THREE [URL: http://referenceworks.brillonline.com/browse/encyclopaedia-of-islam-3/alpha/a?s. start=400; acceso el 21/05/2014].

ESCACENA, J. L.

(1986): “Gadir", [en] G. del Olmo - M. E. Aubet (eds.), Los fenicios en la Península Ibérica, Sabadell, 39-58.

(1993): "De la muerte de Tartesos. Evidencias en el registro poblacional", Spal 2, 183-218 (http://dx.doi.org/10.12795/spal.1993.i2.08).

(2000): "Los negocios del campo, de la industria, del comercio y del mar", [en] C. Aranegui (ed.), Argantonio, rey de Tarteso, Sevilla, 117-135.

(2002): "Murallas fenicias para Tartessos. Un análisis darwinista", Spal 11, 69-105 (http:// dx.doi.org/10.12795/spal.2002.i11.04).

(2004): "Tartessos (des)Orientado", [en] B. Costa - J. H. Fernández (eds.), Colonialismo e Interacción Cultural: El Impacto Fenicio Púnico en las Sociedades Autóctonas de Occidente. XVIII Jornadas de Arqueología Fenicio-Púnica (=Treballs del Museu Arqueologic d'Eivissa i Formentera 54), Ibiza, 7-55. 
(2011): "Variación identitaria entre los orientales de Tarteso. Reflexiones desde el antiesencialismo darwinista", [en] Álvarez (ed.), 2011, 161-184.

(2013): “El espejismo tartésico", [en] Campos - Alvar (eds.), 2013, 137-195.

Escacena, J. L. - García Fernández, F. J. (2012): "La Sevilla protohistórica”, [en] J. Beltrán - O. Rodríguez (eds.), Hispaniae urbes. Investigaciones arqueológicas en ciudades históricas (=Historia y Geografía 203), Sevilla, 763-814.

ESCACENA, J. L. - IZQUIERDo, R.

(2001): "Oriente en Occidente. Arquitectura civil y religiosa en un barrio fenicio de la Caura tartésica”, [en] Ruiz Mata - Celestino (eds.), 2001, 123-157.

(2008): "A propósito del paisaje sagrado fenicio de la paleodesembocadura del Guadalquivir”, [en] X. Dupré - S. Ribichini - St. Verger (eds.), Saturnia Tellus. Definizioni dello spazio consacrato in ambiente etrusco, italico, fenicio-punico, iberico e celtico (Atti del Convegno internazionale svoltosi a Roma dal 10 al 12 novembre 2004), Roma, 431-455.

Escacena, J. L. - VÁzquez, M. I. (2009): “Conchas de salvación”, Spal 18, 53-84 (http:// dx.doi.org/10.12795/spal.2009.i18.04).

Fernández Flores, A. - Rodríguez Azogue, A. (2005): "El complejo monumental del Carambolo Alto, Camas (Sevilla). Un santuario orientalizante en la paleodesembocadura del Guadalquivir", TP 62/1, 86-111 (http://dx.doi.org/10.3989/tp.2005.v62.i1).

FernÁndez Nieto, F. (1999): “Economía de la colonización fenicia y griega en la Península Ibérica", StHis 17, 25-58.

Fernández Uriel, P. - Wagner, C. G. - López Pardo, F. (coords.), (2000): Intercambio y comercio preclásico en el Mediterráneo. Actas del I Coloquio del CEFYP (Madrid, 9-12 de noviembre, 1998), Madrid.

FERRER, E.

(2004): "La religión púnica en Iberia: lugares de culto", [en] A. González Blanco - G. Matilla Séiquer - A. Egea Vivancos (coords.), El mundo púnico: religión, antropología y cultura material. Actas II Congreso Internacional del Mundo Púnico (=Estudios Orientales 5-6), Murcia, 107-118.

(2005): "Fenicios y cartagineses en el Tarteso postcolonial", [en] M. Bendala - M. Belén (dirs.), V Congreso de Historia de Carmona. El nacimiento de la ciudad: la Carmona protohistórica, Sevilla, 195-223.

(2010): "La necrópolis feniciopúnica de Gadir. Reflexiones a partir de un discurso identitario no esencialista”, [en] Niveau de Villedary - Gómez Fernández (eds.), 2010, 69-92.

Filigheddu, P. (2006): "Die Ortsnamen des Mittelmeerraums in der phönizischen und punischen Überlieferung", UF 38, 149-265.

Freedman, D. N. (2000): Eerdmans Dictionary of the Bible, Amsterdam.

GabBay, D. - Woods, J. (2005): A Practical Logic of Cognitive Systems. Volume 2. The Reach of Abduction: Insight and Trial, Amsterdam.

García Alfonso, E. (2000): El impacto colonial fenicio arcaico en el hinterland de Andalucía mediterránea (siglos VIII-VI a.C.). El mundo indígena y las transformaciones del Hierro Antiguo, Tesis Doctoral Inédita. Universidad de Málaga.

García Bellido, A. (1968): España y los españoles hace dos mil años, según la "Geografía" de Estrabón, Madrid. 
García Menárguez, A. - Prados, F. (2014): “La presencia fenicia en la Península Ibérica: el Cabezo Pequeño del Estaño (Guardamar del Segura, Alicante)", TP 71/1, 113-133 (http:// dx.doi.org/10.3989/tp.2014.12127).

García Teysandier, E. - Cabaco, B. (2010): "Hallazgos fenicios en Ayamonte (Huelva): La necrópolis de la Hoya de los Rastros y materiales del hábitat en la Mesa del Tejar”, [en] Pérez Macías - Romero Bomba (eds.), 2010, 31.

GARBINI, G.

(1997): I Filistei. Gli Antagonisti di Israele, Milano.

(1999): "Le origini di Cadice", Rivista di Cultura Classica e Medioevale 41/2, 159-166.

(2001): "Nouvelles perspectives sur la plus ancienne prêsence orientale dans la Péninsule Ibérique", [en] Os púnicos no Extremo Occidente. Actas do coloquio Internacional (Lisboa 27 e 28 de outubro de 2000), Lisboa, 39-45

Gener, J. M. - Navarro, M. Á. - Pajuelo, J. M. - Torres, M. - Domínguez-Bella, S. (2012): "Las crétulas del siglo VIII a.C. de las excavaciones del solar del cine Cómico (Cádiz)", $\operatorname{MDAI}(M)$ 53, 134-186.

Giannakos, K. (2013): “Aegean Type Swords and Finds in Anatolia, Technology of Metals and Structures, Written Sources and the Dating of Trojan War", [en] L. Bombardieri - A. D’Agostino - G. Guarducci - V. Orsi - St. Valentini (eds.), Identity and Connectivity. Proceedings of the 16th Symposium on Mediterranean Archaeology, SOMA 2012 (=BAR International Series 2581, I), Oxford, vol. 1, 427-437.

González de Canales, F. - Serrano, L. - Llompart, J.

(2004): El emporio fenicio precolonial de Huelva (c. 900-770 a.C.), Madrid.

(2006): "The Pre-colonial Phoenician Emporium of Huelva c. 900-770 a.C.", BABesch 81, $13-29$.

(2006a): "Las evidencias más antiguas de la presencia fenicia en el sur de la Península", Mainake 28, 105-128.

(2008): "The emporium of Huelva and phoenician chronology: present and future possibilities", [en] C. Sagona (ed.), Beyond the Homeland: Markers in Phoenician Chronology (=Ancient Near Eastern Studies, Supplement 28), 631-655.

(2008a): "Tarsis y la monarquía unificada de Israel”, Gerión 26/1, 61-88.

(2009): "The two phases of Western Phoenician expansion beyond the Huelva finds: an interpretation", $A W E$ 8, 1-20.

(2010): "El inicio de la Edad del Hierro en el suroeste de la Península Ibérica. Las navegaciones precoloniales y cuestiones en torno a las cerámicas locales de Huelva", [en] Pérez Macías - Romero Bomba (eds.), 2010, 648-698.

Hodos, T. (2011): “A Phoenician past and present”, BRIIFS 13, 23-46.

$I C O=$ M. G. Amadasi, Le iscrizioni fenici e puniche delle colonie in Occidente, Roma, 1967.

ISBE (1915): The International Standard Bible Encyclopaedia, Chicago, vol. 2.

JimÉnez Ávila, J. (2002): La toréutica orientalizante en la Península Ibérica (=Publicaciones del Gabinete de Antigüedades de la Real Academia de la Historia, Bibliotheca Archaeologica Hispana 16; Studia Hispano-Phoenicia 2), Madrid.

López Castro, J. L. (2013): "La sociedad tartesia y la sociedad fenicia occidental", [en] Campos - Alvar (eds.), 2013, 511-528. 
LóPez PARdo, F. (2004): “Crono y Briareo en el umbral del Océano. Un recorrido por la historia mítica de los viajes al confín del Occidente hasta los albores de la colonización", [en] V. Peña - C. G. Wagner - A. Mederos (eds.), La navegación fenicia. Tecnología naval y derroteros. Encuentro entre marinos, arqueólogos e historiadores, Madrid, 1-42.

MARÍn, M. C.

(2011): "La singularidad religiosa de Gadir en el mundo fenicio-púnico", [en] Álvarez (ed.), 2011, 213-222.

(2011a): "El Kronion de Gadir: una propuesta de análisis", [en] M. C. Marín (coord.), Cultos y ritos de la Gadir fenicia (=Monografías Historia y Arte 192), Cádiz, 221-245.

Marín, M. C. - JimÉnez, A. M. (2013): “El capitel protoeólico de Cádiz”, [en] Arruda (ed.), 2014, vol. 1, 120-128.

Mateos, P. - Celestino, S. - Pizzo, A. - Tortosa, T. (eds.), (2009): Santuarios, oppida y ciudades: arquitectura sacra en el origen y desarrollo urbano en el Mediterráneo Occidental (=Anejos de AEspA 45), Mérida.

Mederos, A. - Escribano, G. (2005): "El comercio de sal, salmones y garum en el litoral atlántico norteafricano durante la Antigüedad", Empúries 54, 231-246.

Mederos, A. - Ruiz Cabrero, L. A.

(2006): "Los inicios de la presencia fenicia en Málaga, Sevilla y Huelva”, Mainake 28, $129-176$.

(2011): “Sidón en Occidente. El Castillo de Doña Blanca, Asido y Gadir", [en] Álvarez (ed.), 2011, 87-117.

Moreno, F. J.

(2000): “Tarteso, estelas, modelos pesimistas”, [en] Fernández Uriel - Wagner - López Pardo (coords.), 2000, 153-174.

(2008): “En El corazón de las tinieblas. Forma y dinámica en la colonización fenicia de Occidente", Gerión 26/1, 35-60.

Moret, P. (2006): "La formation d'une toponymie et d'une ethnonymie grecques de l'Ibérie: étapes et acteurs", [en] G. Cruz Andreotti - P. Le Roux - P. Moret (eds.), La invención de una geografía de la Península Ibérica. I. La época republicana, Málaga-Madrid, 39-76.

NaïT-Zerrad, K. (2002): Dictionnaire des racines berbères (formes attestées). III. D-Gey, Paris-Louvain.

Niveau de Villedary, A. M.

(2008): "Estado de la cuestión y nuevas perspectivas de la Arqueología púnica en la Península Ibérica: el caso de la bahía de Cádiz”, [en] J. P. Vita - J. Á. Zamora (eds.), Nuevas Perspectivas II: La arqueología fenicia y púnica en la península ibérica (=CuadAMed 18), Barcelona, 81-127.

(2010): "Deconstruyendo paradigmas. Una (re)visión historiográfica crítica al modelo interpretativo tradicional del Cádiz feniciopúnico a la luz de los nuevos datos", [en] E. Ferrer (coord.), Los púnicos de Iberia: proyectos, revisiones, síntesis (=Mainake 32/1), Málaga, 619-671.

Niveau de Villedary, A. M. - Gómez Fernández, V. (EDs.), (2010): Las necrópolis de Cádiz. Apuntes de arqueología gaditana en homenaje a F. J. Sibón Olano, Cádiz.

Olmos, R. (1986): "Los griegos en Tarteso: replanteamiento arqueológico-histórico del problema”, [en] Homenaje a Luis Siret (1934-1984), Sevilla, 584-599. 
ORDÓÑEZ, R.

(2011): La crisis del siglo VI a.C. en las colonias fenicias del Occidente mediterráneo: Contracción económica, concentración poblacional y cambio cultural, Tesis Doctoral, Universidad de Oviedo.

(2012): "Identidad y conflicto en el mundo fenicio peninsular: una aproximación desde el postcolonialismo", Herakleion 5, 5-25.

Pellicer, M.

(1996): "Huelva tartesia y fenicia", RStudFen 24/2, 119-140.

(2006): "Momentos precoloniales y precolonización en Iberia. Nuevos datos", RStudFen 34, 9-37.

Perea, A. - Cabrera, A. - Feliú, M. J. - Gayo, M. D. - Gener, J. M. - Montero I. - Pajuelo, J. M. (2004): "El ajuar de oro de la tumba fenicia del Obispo, Gades", [en] A. Perea - I. Montero - Ó. García-Vueltas (eds.), Tecnología del oro antiguo: Europa y América (=Anejos de AEspA 32), Madrid, 231-242.

PeIRCE, C. S.

(1992): "Deduction, Induction, and Hypotesis", [en] N. Houser - C. Kloesel (eds.), The Essential Peirce. Selected Philosophical Writings. Volume 1 (1867-1893), Bloomington, IN, 196-199.

(1998): "Pragmatism and the logic of Abduction", [en] The Essential Peirce. Selected Philosophical Writings. Volume 2 (1893-1913), Bloomington, IN, 226-241.

Pérez Macías, J. A. - Romero Bomba, E. (eds.), (2010): IV Encuentro de Arqueología del Suroeste Peninsular (=Collectanea 145), Huelva.

Pilkington, N. (2012): “A Note on Nora and the Nora Stone”, BASOR 365, 45-51.

PlÁcido, D. (1993): “La imagen griega de Tarteso”, [en] Alvar - Blázquez (eds.), 1993, 81-90.

Prados, F. - Blánquez, J. J. (2007): “Las fortificaciones coloniales en la Península Ibérica: de los modelos orientales a los sistemas púnico-helenísticos", [en] Berrocal-Rangel - Moret (eds.), 2007, 57-74.

Presedo, F. J. (1981): "Nuevos datos sobre colonización fenicia”, [en] Primera Reunión Gallega de Estudios Clásicos (Santiago-Pontevedra, 2-4 julio 1979), Santiago de Compostela, 24-31.

RAMÓN, J. (2006): “La proyección comercial mediterránea y atlántica de los centros fenicios malagueños en época Arcaica”, Mainake 28, 189-212.

Ribichini, S. (2000): "Sui miti della fondazione di Cadice", [en] Actas del IV Congreso Internacional de Estudios Fenicios y Púnicos. Cádiz, 2 al 6 de octubre de 1995, Cádiz, 661-668.

Rodero, V. - Berrocal-Rangel, L. (2011-2012): “Análisis morfoestructural de la arquitectura defensiva en el ámbito indígena y colonial de la protohistoria antigua peninsular ( $\mathrm{ca}$. 1000 - 600 a.C.)", CuPAUAM 37-38, 223-239.

Rodríguez MuÑoz, R. (2004): “Análisis de los espacios domésticos y comunitarios en la arquitectura prerromana de Huelva", Saguntum 36, 53-60.

Rufete, P. (2002): El final de Tartessos y el periodo turdetano en Huelva (=Huelva Arqueológica 17), Huelva, 2002.

RuIz MATA, D.

(1998): "Turdetanos: origen, territorio y delimitación del tiempo histórico", REstIb. 3, 153221. 
(1999): "La fundación de Gadir y el Castillo de Doña Blanca: contrastación textual y arqueológica", Complutum 10, 279-317.

(2001): "Arquitectura y urbanismo en la ciudad protohistórica del Castillo de Doña Blanca (El Puerto de Santa María, Cádiz)”, [en] Ruiz Mata - Celestino (eds.), 2001, 261-274.

Ruiz Mata, D. - Celestino, S. (EDs.), (2001): Arquitectura oriental y orientalizante en la Península Ibérica (=Lenguas y culturas del Antiguo Oriente Próximo 4), Madrid.

SÁEz, A. M.

(2009): "El templo de Melqart de Gadir: hito religioso-economico y marítimo. Consideraciones sobre su relación con la industria conservera", [en] Mateos et alii (eds.), 2009, 115-130.

(2010): "La producción alfarera y la economía salazonera de Gadir: balance y novedades", Mainake 32/2, 885-932.

Sáez, A. M. - Montero, A. I. - Díaz Rodríguez, J. J. (2005): "Nuevos vestigios del santuario gadirita de Melqart en Sancti Petri (San Fernando, Cádiz)", [en] Celestino Pérez - Jiménez Ávila (eds.), 2005, vol. 2, 873-878.

SANMARTín, J. (1994): “Toponimia y antroponimia: fuentes para el estudio de la cultura púnica en España", [en] A. González - J. L. Cunchillos - M. Molina (coords.), El mundo púnico. Historia, sociedad y cultura, Murcia, 227-247.

Torres, M. (2010): “Sobre la cronología de la necrópolis fenicia arcaica de Cádiz”, [en] Niveau de Villedary - Gómez Fernández (eds.), 2010, 31-67.

Tovar, A. (1974): Iberische Landeskunde. II. Baetica, Baden-Baden.

THA I = J. Mangas - D. Plácido (eds.), Avieno. Ora Maritima. Descriptio orbis terrae. Phaenomena (=Testimonia Hispaniae Antiqua I), Madrid, 1994.

THA IIA = J. Mangas - D. Plácido (eds.), La Península Ibérica en los autores griegos: de Homero a Platón (=Testimonia Hispaniae Antiqua IIA), Madrid, 1998.

THA IIB = J. Mangas - D. Plácido (eds.), La Península Ibérica prerromana de Éforo a Eustacio (=Testimonia Hispaniae Antiqua IIB), Madrid, 1999.

Tsirkin, J. B. (2007): “Arcaleo, fundador de Gadir”, Polis 19, 163-178.

VALDÉs, M. (2013): “Afrodita y los fenicios en el Egeo”, Gerión 31, $51-87$ (http://dx.doi. org/10.5209/rev_GERI.2013.v31.43613).

WAGNeR, C. G.

(2000): "Comercio lejano, colonización e intercambio desigual en la expansión fenicia arcaica por el Mediterráneo”, [en] Fernández Uriel - Wagner - López Pardo (coords.), 2000, 79-91.

(2005): "Fenicios en el Extremo Occidente: conflicto y violencia en el contexto colonial arcaico", RPA 8/2, 177-192.

(2007): "El barco negro en la costa. Reflexiones sobre el miedo y la colonización fenicia en la tierra de Tarsis", [en] D. Plácido - F. J. Moreno - A. Ruiz (eds.), Necedad, sabiduría y verdad: el legado de Juan Cascajero (=Gerión, Extra 1), Madrid, 121-131.

(2011): “Fenicios en Tartessos: ¿Interacción o colonialismo?”, [en] Álvarez (ed.), 2011, 119-128.

Wallis Budge, E. A. (1991): A hieroglyphic vocabulary to the Book of the Dead, Mineola, NY (1 $1^{\text {a }}$ ed., London, 1911). 
ZAmora, J. Á. (2006): "La «ciudad nueva»: la fundación de ciudades en el mundo feniciopúnico", [en] M. J. Iglesias - R. Valencia - A. Ciudad (eds.), Nuevas ciudades, nuevas patrias. Fundación y relocalización de ciudades en Mesoamérica y el Mediterráneo Antiguo, Madrid, 331-368.

Zamora, J. Á. - Gener, J. M. - Navarro, M. D. L. Á. - Pajuelo, J. M. - Torres, M. (2010): "Epígrafes fenicios arcaicos en la excavación del Teatro Cómico de Cádiz (2006-2010)", RStFen 38/2, 203-236. 